Het effect van schoolmelk op zuivelconsumptie en andere dranken bij kinderen

Metingen op school en oudervragenlijst

Oktober 2021: Gertrude G. Zeinstra \& Meeke Ummels
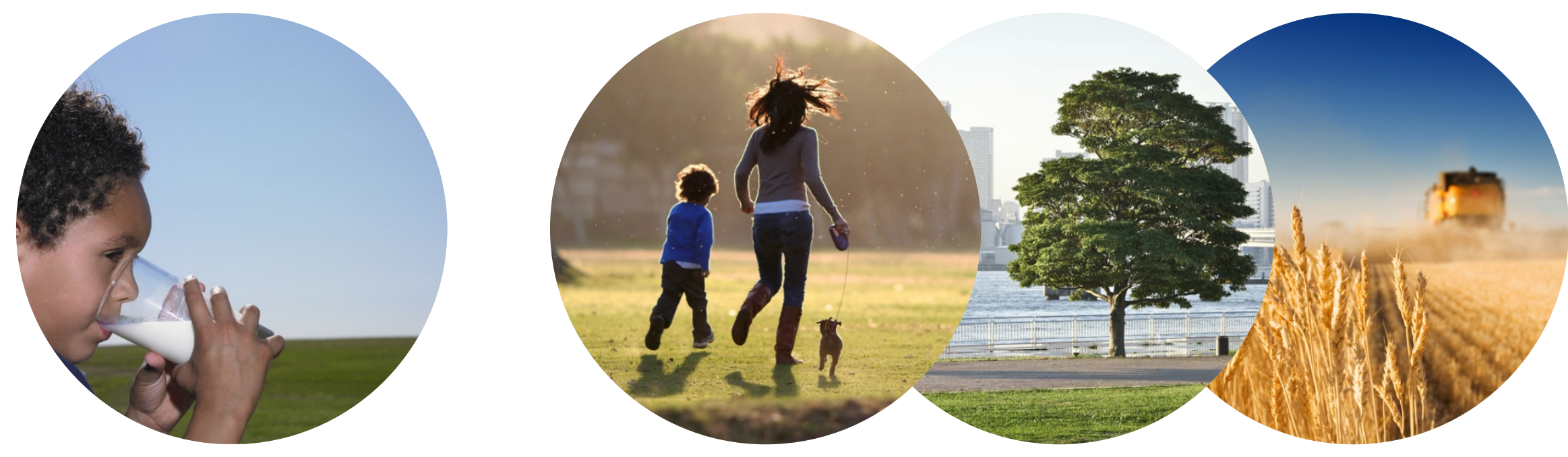


\section{Het effect van schoolmelk op zuivelconsumptie en andere dranken bij kinderen}

Report 2204, Final

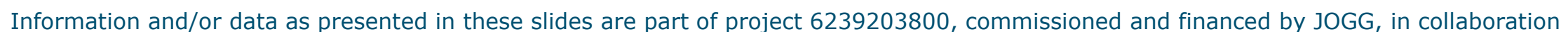

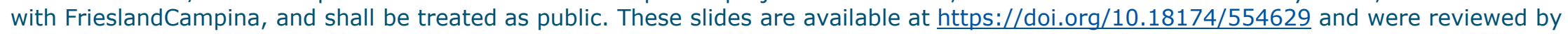

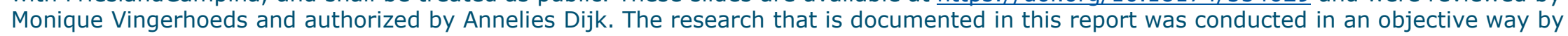
researchers who act impartial with respect to the client(s) and sponsor(s).

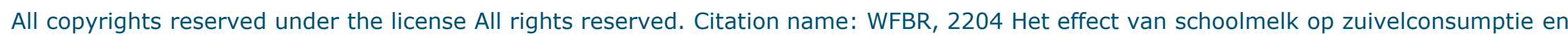
andere dranken bij kinderen.

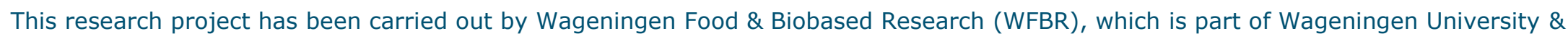
Research.

PO box 17, 6700 AA Wageningen, The Netherlands, T + 31 (0)317 4800 84, E info.wfbr@wur.nl, www.wur.eu/wfbr. 


\section{Inhoudsopgave}

- Achtergrond \& doel

- Onderzoeksmethode

- Resultaten metingen op school

- Wat drinken kinderen op school?

- Welke hoeveelheden drinken kinderen op school?

- Resultaten oudervragenlijst

- Discussie + aanbevelingen

- Conclusie 


\section{Achtergrond}

- Zuivel staat in de Schijf van Vijf, vanwege:

- Goede voedingsstoffen (eiwit, vitamines B2, B12 en calcium)

- Verlagen risico darmkanker + diabetes (Gezondheidsraad, 2015)

- Zuivelinname in Nederland daalt, ook bij kinderen (VCP 2012-2016)

- Jonge kinderen drinken veel suikerhoudende dranken (VCP 2012-2016) $\rightarrow$ mogelijke relatie met overgewicht (Luger et al, 2017)

- FrieslandCampina heeft een vernieuwd concept van het Schoolmelkprogramma (20 weken lang 2-3x per week gratis (karne)melk + yoghurt op school; geleverd in 1-1.5 liter-pakken) 


\section{Doel \& onderzoeksvragen}

Inzicht krijgen in het effect van het vernieuwde schoolmelk concept op de inname van zuiveldranken en andere dranken van kinderen op de basisschool.

Onderzoeksvragen:

- Hoeveel kinderen doen mee met het Schoolmelk-programma?

- Welke dranken drinken de kinderen op school?

- Hoeveel consumeren zij van deze dranken op school?

- Wat zijn de verschillen tussen wel of niet een Schoolmelk-dag?

- Welke ervaringen hebben ouders met het Schoolmelk-programma (o.a. effecten bij hun kind \& consumptie thuis)? 


\section{Methode}

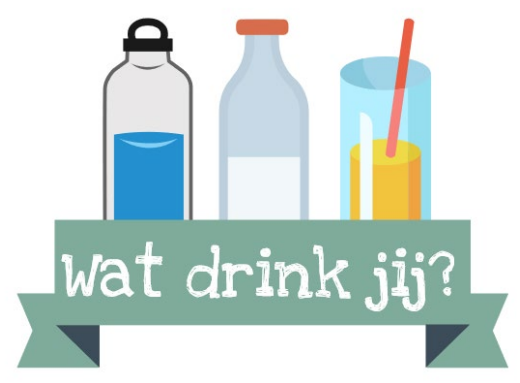




\section{Methode 1}

Twee onderdelen:

1. Metingen op school om daadwerkelijke consumptie te meten

2. Oudervragenlijst om ervaringen van ouders met het Schoolmelk-programma te meten

- Goedkeuring van Sociaal Ethische Commissie

- Inclusiecriteria scholen:

- In JOGG-gemeente

- Op max. 1 uur rijden van Wageningen

- Ouders ontvingen een informatiebrief en gaven toestemming voor deelname van hun kind 


\section{Methode 2: Metingen op school (a)}

- Kinderen groep 6 t/m 8 (9-12 jaar)

- 3 scholen*: 3-4 klassen per school

- Twee meetdagen:

- 1 schoolmelk-dag

- 1 niet-schoolmelk-dag

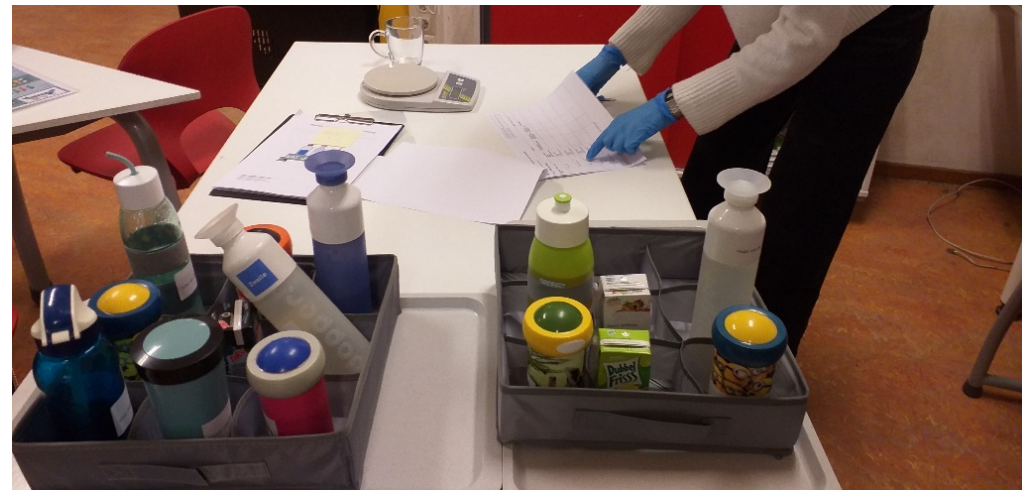

- Meetprotocol drankenconsumptie tijdens 'Schoolmelk'-moment:

- Volle beker (pakje) wegen voor drinkmoment

- Lege(re) beker (pakje) wegen na drinkmoment

- Registratie soort drank (waar nodig: navragen bij kind) 


\section{Methode 3: Metingen op school (b)}

- Binnen dit project is ervoor gekozen om bij alle kinderen met toestemming te meten, want:

- Kinderen bepalen per dag en ter plekke of zij wel of niet schoolmelk gaan drinken (er is geen vaste groep kinderen die op vaste dagen deelneemt aan het Schoolmelk-programma).

- We wilden mogelijke indirecte effecten van het Schoolmelkprogramma in kaart brengen bij kinderen die geen school(karne)melk drinken (maar bijvoorbeeld 'eigen' melk meebrengen of een andere gezonde keuze maken op een schoolmelk-dag). 


\section{Methode 4: Oudervragenlijst}

- 9 Schoolmelk basisscholen (3 van metingen op school + 6 andere scholen)

- Ouders met kinderen in groep 1 t/m $8 *$

- Gebruikelijke drank van het kind (soort) voor 6 eetmomenten op 3 dagen:

- Gewone (volledige) schooldag

- Schoolmelk-dag

- Weekenddag

- Ouderpercepties/houding t.o.v. melk en karnemelk **

- Ouderervaringen t.a.v. Schoolmelk-programma inclusief ervaren effecten van het programma op welke dranken het kind (gezin) drinkt **

- Demografische gegevens 


\section{Tijdspad dataverzameling 2021}

\begin{tabular}{|c|c|c|}
\hline & Meetdagen & Oudervragenlijst \\
\hline School 1 & $\begin{array}{l}\text { Maandag } 22 \text { maart: geen Schoolmelk } \\
\text { Vrijdag } 26 \text { maart: Schoolmelk }\end{array}$ & Donderdag 8 april \\
\hline School 2 & $\begin{array}{l}\text { Woensdag } 14 \text { april: Schoolmelk } \\
\text { Maandag } 19 \text { april: geen Schoolmelk }\end{array}$ & Vrijdag 30 april \\
\hline School 3 & $\begin{array}{l}\text { Dinsdag } 18 \text { mei: Schoolmelk } \\
\text { Vrijdag } 21 \text { mei: geen Schoolmelk }\end{array}$ & Woensdag 2 juni \\
\hline School 4 t/m 9 & - & Donderdag 3 juni \\
\hline
\end{tabular}




\section{Analyses en aannames}

- Metingen op school:

- Drankenconsumptie $=$ [gewicht voor $]-$ [gewicht na $]$

- Gemiddelden + SD* of Frequenties (\%) berekend

- Schoolmelk-dag + niet-schoolmelk-dag vergeleken: beschrijvend en/of getoetst a.d.h.v. (gepaarde) t-toets, Chi-kwadraat of ANOVA

- Indien suikerinhoud van de drank onbekend, dan uitgegaan van de reguliere variant (met suiker)

- Oudervragenlijst:

- Frequenties (\%) berekend, beschrijvend

- Gemiddelden + SD* berekend, t-toets en Spearman correlatie

- Uitgangspunt: $p<0.05$ is statistisch significant 


\section{Operationalisatie zuivel en suikerhoudende dranken}

\begin{tabular}{lcc} 
& Zuivel & Suikerhoudende drank \\
\hline Melk + karnemelk & Ja & Nee \\
\hline Water + thee zonder suiker * & Nee & Nee \\
\hline Thee met suiker & Nee & Ja \\
Gezoete melkdranken & Ja & Ja \\
Melkdranken zoetstof (0\% suiker) & Ja & Nee \\
\hline Limonade, ranja (regular) & Nee & Ja \\
\hline Frisdranken regular & Nee & Nee \\
\hline Light-frisdranken & Nee & Ja \\
Vruchten- of groentesappen & Nee & Ja \\
Vruchtendranken & Nee & Nee \\
\hline Plantaardige dranken $* *$ & Nee & Ja
\end{tabular}

* Thee zonder suiker werd niet gedronken in dit onderzoeksproject tijdens de meetdagen op school; in de resultatenslides van de metingen op school is deze categorie genoteerd als 'water'

** Soja-, amandel-, rijst-, haver-, en kokosdrink 


\section{Impressie uitvoer + gebruikte drankenkaart}
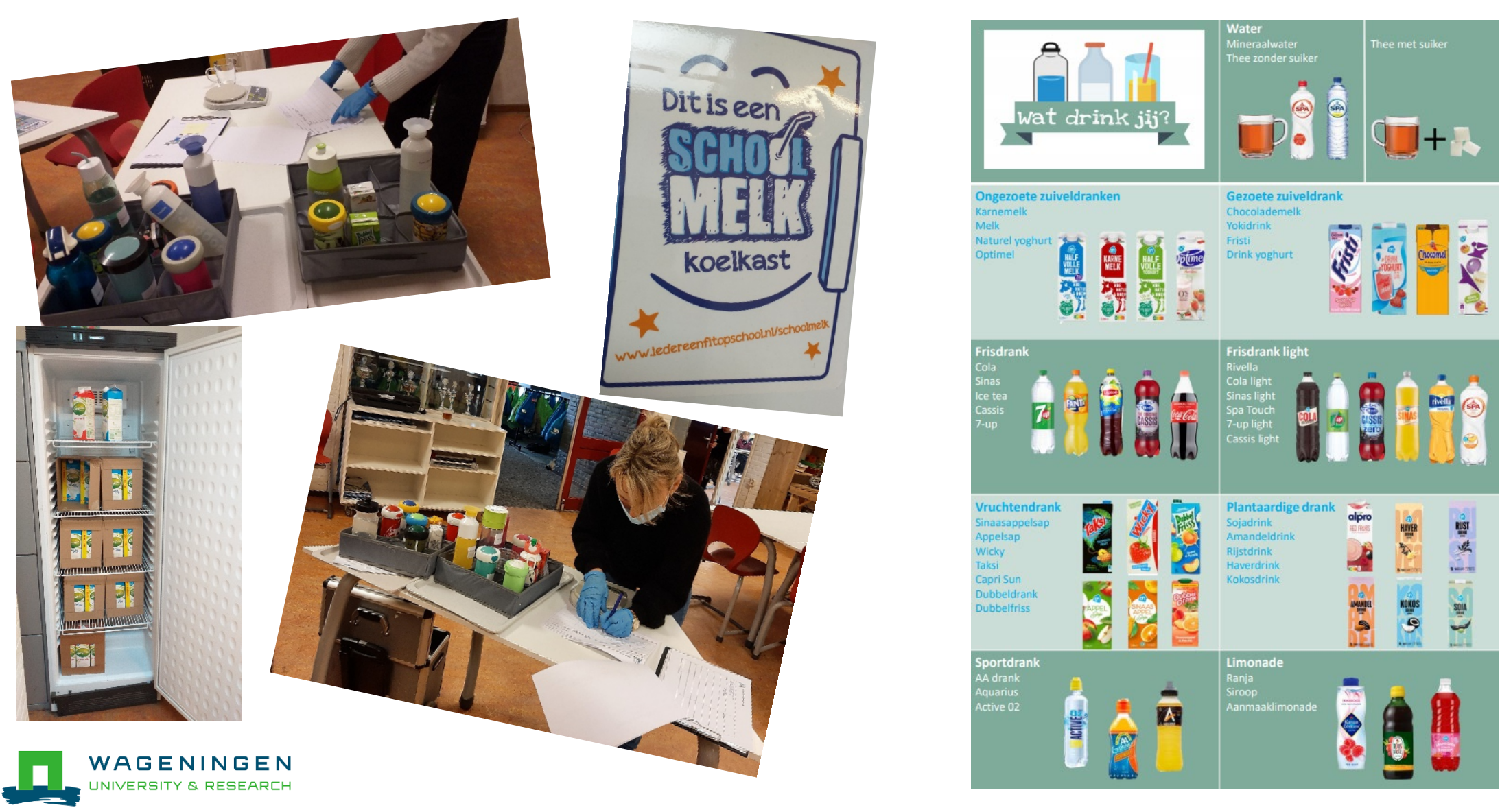


\section{Resultaten metingen op school}

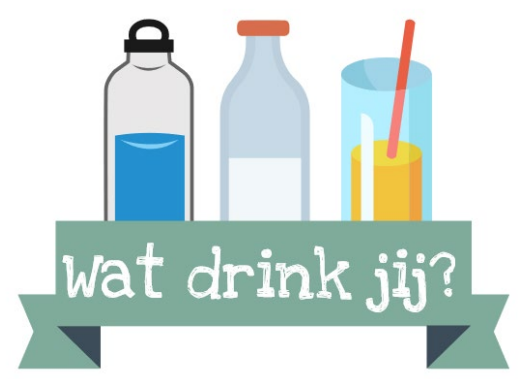




\section{Kenmerken van de drie scholen:}

\begin{tabular}{|c|c|c|c|c|c|c|}
\hline & Locatie & Rooster & Beleid drinken & Schoolmelk-dagen & $\begin{array}{c}\text { Tijdstip } \\
\text { Schoolmelk }\end{array}$ & $\begin{array}{c}\text { Toestemming } \\
\text { ouders metingen }\end{array}$ \\
\hline School 1 & Apeldoorn & Continu & - & $\begin{array}{c}\text { Woensdag, } \\
\text { donderdag en vrijdag }\end{array}$ & $\begin{array}{c}\text { Tijdens de } \\
\text { lunchpauze: } \\
11.45-12.00 \text { uur }\end{array}$ & Digitaal (via app) \\
\hline School 2 & Utrecht & Continu & - & $\begin{array}{c}\text { Dinsdag, woensdag, } \\
\text { donderdag. } \\
\text { Proberen de hele } \\
\text { week te schenken. }\end{array}$ & $\begin{array}{c}\text { Tijdens de } \\
\text { lunchpauze: } \\
12.00-12.15 \text { uur }\end{array}$ & $\begin{array}{c}\text { Digitaal (via } \\
\text { nieuwsbrief en } \\
\text { app) }\end{array}$ \\
\hline School 3 & Almere & Regulier & $\begin{array}{c}\text { Water } \\
\text { ochtendpauze }\end{array}$ & $\begin{array}{l}\text { Dinsdag en } \\
\text { donderdag }\end{array}$ & $\begin{array}{c}\text { Tijdens de } \\
\text { ochtendpauze: } \\
10.15 \text { en } 10.45 \text { uur }\end{array}$ & $\begin{array}{l}\text { Digitaal (via app) } \\
\text { en papieren versie }\end{array}$ \\
\hline
\end{tabular}




\section{Deelnemers metingen op school}

\begin{tabular}{|c|c|c|c|c|c|}
\hline & Klassen & $\begin{array}{c}\text { Uitgenodigd } \\
\mathrm{N}\end{array}$ & $\begin{array}{c}\text { Toestemming } \\
\text { N (\%) }\end{array}$ & $\begin{array}{c}\text { Verwachte toestemming } \\
\text { door school } \\
\mathrm{N}(\%)\end{array}$ & $\begin{array}{c}\text { Beide meetdagen } \\
\text { gemeten } \\
\mathrm{N}(\%)\end{array}$ \\
\hline School 1 & $\begin{array}{c}4: \\
6 \mathrm{~A}, 6 \mathrm{~B}, 7 \& 8\end{array}$ & 109 & $65(60 \%)$ & $98(90 \%)$ & $54(47 \%)$ \\
\hline School 2 & $\begin{array}{c}4: \\
5 / 6,6,7 \& 8\end{array}$ & 85 & $18(21 \%)$ & $85(100 \%)$ & $10(9 \%)$ \\
\hline School 3 & $\begin{array}{c}3: \\
5 / 6,7 \& 8\end{array}$ & 83 & $53(64 \%)^{*}$ & $17(20 \%)$ & $50(44 \%)$ \\
\hline Totaal & 11 & 277 & $136(49 \%)$ & $200(72 \%)$ & $114(41 \%)$ \\
\hline
\end{tabular}

*Naast digitaal consent ook 'papieren informed consent' aangeboden

Toestemming voor deelname was lager dan verwacht door school Onderzoeksgroep metingen op school: 114 kinderen 


\section{Demografische kenmerken kinderen $(N=114)$ : geslacht en leeftijd}

\begin{tabular}{lccc|lcc|} 
School & N & Jongens: N (\%) & Meisjes: N(\%) & School & N & Leeftijd (Gem. \pm SD) \\
\hline School 1 & 54 & $34(63 \%)$ & $20(37 \%)$ & School 1 & 54 & $10,7 \pm 1,1$ \\
\hline School 2 & 10 & $5(50 \%)$ & $5(50 \%)$ & School 2 & 10 & $9,9 \pm 0,6$ \\
School 3 & 50 & $25(50 \%)$ & $25(50 \%)$ & School 3 & 50 & $10,9 \pm 1,3$ \\
\hline Totaal & 114 & $64(56 \%)$ & $50(44 \%)$ & Totaal & 114 & $10,7 \pm 1,2$
\end{tabular}

De gemiddelde leeftijd van de deelnemende kinderen was 10,7 jaar (Range 7 - 14 jaar). Er deden iets meer jongens mee (56\%) dan meisjes (44\%). 


\section{Demografische kenmerken kinderen: groepen}

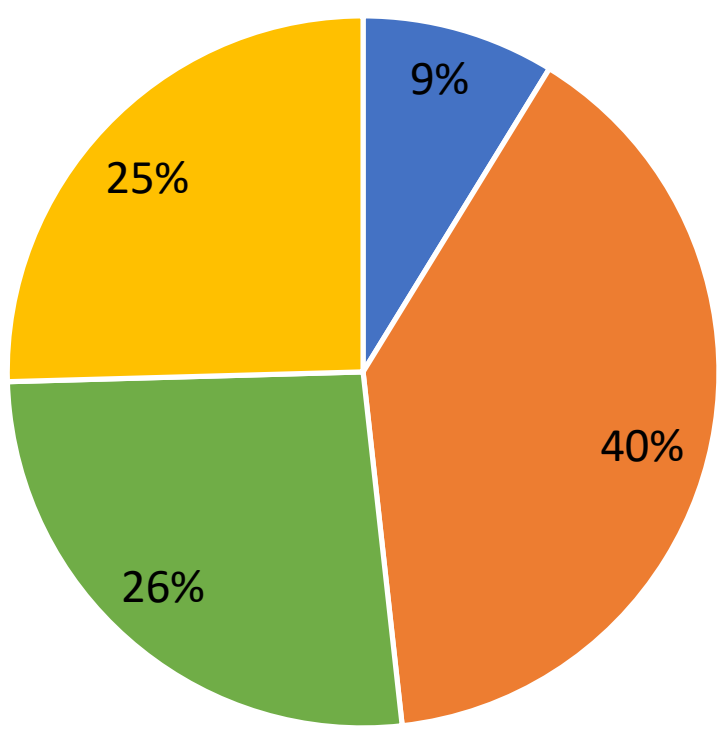

- Groep 5

- Groep 6

- Groep 7

Groep 8

Het onderzoek richtte zich op groep 6-7-8 $40 \%$ van de kinderen zat in groep 6

Op twee scholen is er een groep 5-6 klas geïncludeerd 


\section{Hoeveel kinderen doen mee met het Schoolmelk-programma?}

\begin{tabular}{|c|c|c|c|c|}
\hline School & N & Schoolmelk: N (\%) & Schoolkarnemelk: N (\%) & Deelname totaal \\
\hline School 1 & 54 & $19(35 \%)$ & - & $19(35 \%)$ \\
\hline School 2 & 10 & $7(70 \%)$ & - & $7(70 \%)$ \\
\hline School 3 & 50 & $6(12 \%)$ & $1(2 \%)$ & $7(14 \%)$ \\
\hline Totaal & 114 & $32(28 \%)$ & $1(1 \%)$ & $33(29 \%)$ \\
\hline \multicolumn{5}{|c|}{$\begin{array}{l}29 \% \text { van de deelnemende kinderen dronk (karne)melk vanuit het Schoolmelk-programma } \\
\text { tijdens de schoolmelk-dag. } \\
\text { Deelname aan het programma verschilt tussen de drie scholen (Chi-kwadraat } p<0.001 \text { ), dit } \\
\text { komt met name door school } 2 \text { en in mindere mate door school } 3 \text {. De lagere deelname bij } \\
\text { school } 3 \text { zou mogelijk verklaard kunnen worden door het feit dat deze school een } \\
\text { drinkwaterbeleid heeft, een regulier schoolrooster en de ochtendpauze als drinkmoment } \\
\text { heeft (niet de lunch zoals school } 1 \text { en } 2 \text { ). }\end{array}$} \\
\hline
\end{tabular}




\section{Welke dranken drinken kinderen op school?}




\section{Wat drinken kinderen op school (11 categorieën)?}

\begin{tabular}{lcc}
\hline & Niet-schoolmelk-dag: N (\%) & Schoolmelk-dag: N (\%) \\
\hline Water & $61(53 \%)$ & $51(45 \%)$ \\
Melk + karnemelk & $11(10 \%)$ & $34(30 \%)$ \\
Limonade, ranja (regular) & $20(17 \%)$ & $9(8 \%)$ \\
Vruchtendranken & $5(4 \%)$ & $6(5 \%)$ \\
Gezoete melkdranken & $4(3 \%)$ & $2(2 \%)$ \\
Vruchten- of groentesappen & $4(3 \%)$ & $3(3 \%)$ \\
Melkdranken zoetstof (0\% suiker) & $3(3 \%)$ & $3(1 \%)$ \\
Light-frisdranken & $3(3 \%)$ & $1(1 \%)$ \\
\hline Frisdranken regular & - & - \\
\hline Thee met suiker & - & - \\
\hline Plantaardige dranken & $3(3 \%)$ & $4(3 \%)$ \\
\hline Beker leeg (missing) & $114(100 \%)$ & $114(100 \%)$ \\
\hline Totaal & - & $3 \%)$ \\
\hline
\end{tabular}

Top 3 gedronken dranken op school: water, (karne)melk en limonades

Schoolmelk-dag: meer kinderen drinken (karne)melk; minder kinderen drinken water en limonades 


\section{Hoeveel kinderen drinken hetzelfde op beide dagen?}

\begin{tabular}{|lc|}
\hline Op beide dagen & N \\
\hline Water & 45 \\
\hline Melk + karnemelk & 9 \\
\hline Limonade, ranja & 8 \\
\hline Gezoete melkdranken & 2 \\
\hline Melkdranken zoetstof & 1 \\
\hline Light-frisdranken & 1 \\
\hline Vruchtendranken & 1 \\
\hline Totaal & $\mathbf{6 7}(\mathbf{5 9 \% )}$
\end{tabular}

67 kinderen (59\%) drinken op beide dagen (schoolmelk-dag \& niet-schoolmelk-dag) dezelfde drank 


\section{Hoeveel kinderen drinken water per school?}

\begin{tabular}{lcc} 
& $\begin{array}{c}\text { Niet-schoolmelk-dag } \\
\mathbf{N}(\%)\end{array}$ & $\begin{array}{c}\text { Schoolmelk-dag } \\
\mathbf{N}(\%)\end{array}$ \\
\hline School $\mathbf{1}(\mathbf{N = 5 4 )}$ & $16(26 \%)$ & $11(22 \%)$ \\
\hline School $\mathbf{2}(\mathbf{N = 1 0 )}$ & $7(12 \%)$ & $3(6 \%)$ \\
School 3 $(\mathbf{N = 5 0 )}$ & $38(62 \%)$ & $37(72 \%)$ \\
\hline Totaal & $61(54 \%)$ & $51(45 \%)$
\end{tabular}

Op school 3, met waterdrinkbeleid, drinken meer kinderen water (62$72 \%$ ) dan op de andere twee scholen.

Het waterdrinkbeleid van school 3 lijkt dus invloed te hebben op hoeveel kinderen water drinken. 


\section{Verschuiving binnen kinderen t.a.v. zuivel $(N=113)$}

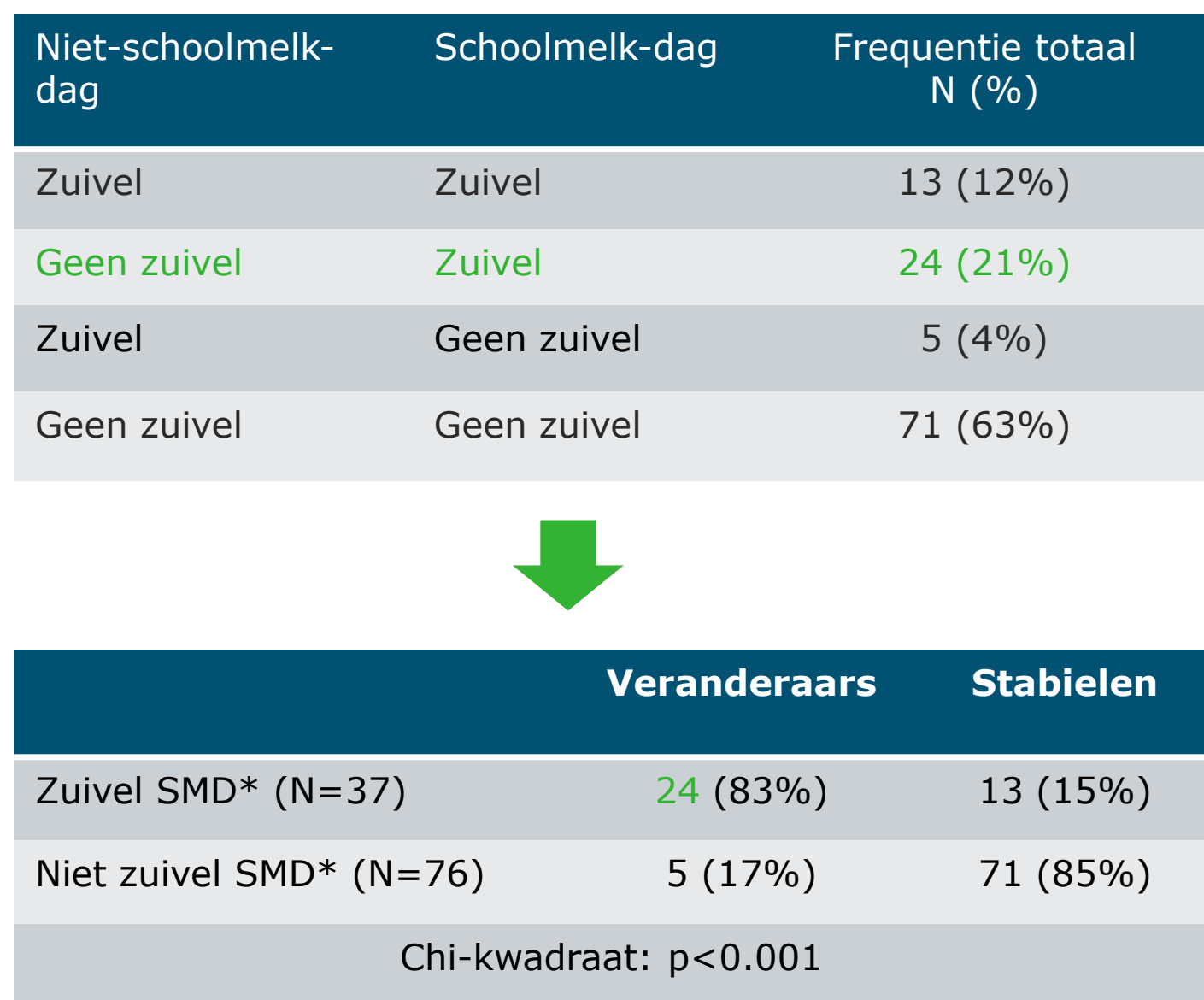

$63 \%$ drinkt op beide dagen geen zuivel en $12 \%$ drinkt zuivel op beide dagen, dus de meeste kinderen veranderen niet (75\%).

$21 \%$ van de kinderen gaat van geen zuivel naar zuivel, terwijl $4 \%$ de andere kant op verandert.

De Chi-kwadraat toets laat een significante relatie zien tussen soort drank en dag: het aantal kinderen dat zuivel gaat drinken $(\mathrm{N}=24)$ is hoger dan verwacht; aantal kinderen dat de andere kant op beweegt $(\mathrm{N}=5)$ lager dan verwacht op basis van de geobserveerde waardes. 


\section{Inzoomen op veranderaars: geen zuivel $\rightarrow$ zuivel $(N=24)$}

\section{Hoe zit het met suikerhoudende zuiveldranken?}

\begin{tabular}{lcc}
\hline Niet-schoolmelk-dag & Schoolmelk-dag & $\mathrm{N}$ \\
\hline Water & Karnemelk & 1 \\
Water & Schoolmelk & 13 \\
\hline Leeg & Schoolmelk & 1 \\
\hline Vruchtensap & Schoolmelk & 1 \\
Vruchtensap & Schoolmelk-karnemelk & 1 \\
Vruchtendrank & Schoolmelk & 2 \\
Limonade, ranja, siroop, diksap & Schoolmelk & 5 \\
\hline & & $\mathbf{2 4}$
\end{tabular}

De kinderen die zuivel zijn gaan drinken op een schoolmelk-dag $(\mathrm{N}=24)$, drinken op die dag geen zuiveldranken met toegevoegd suiker.

Bij 14 van de 24 gaat het om een verschuiving van water naar zuivel zonder suiker.

Bij 9 van de 24 gaat het om een verschuiving van suikerhoudende dranken naar zuivel zonder suiker.

23 van deze 24 kinderen dronken op de schoolmelkdag (karne)melk vanuit het Schoolmelk-programma. 


\section{Inzoomen op de stabiele zuivel groep $(\mathrm{N}=13)$ :}

\section{Hoe zit het met suikerhoudende zuiveldranken?}

\begin{tabular}{lcc}
\hline Niet-schoolmelk-dag & Schoolmelk-dag & N \\
\hline Melk, halfvol & Schoolmelk & 5 \\
\hline Schoolmelk* & Schoolmelk & 4 \\
Gezoete melkdranken & Schoolmelk & 1 \\
Gezoete melkdranken & Gezoete melkdranken & 3 \\
\hline & & $\mathbf{1 3}$
\end{tabular}

Van de kleine groep stabiele zuiveldrinkers (zuivel op beide dagen), drinken de meesten (9 v/d 13) ongezoete zuivel op beide dagen

Eén kind verandert van gezoete naar ongezoete zuivel

Drie kinderen drinken op beide dagen gezoete zuivel

10 van deze 13 kinderen dronken op de schoolmelk-dag (karne)melk vanuit het Schoolmelk-programma. 


\section{Verschuiving binnen kinderen t.a.v. suiker}

\begin{tabular}{|c|c|c|}
\hline $\begin{array}{l}\text { Niet-schoolmelk- } \\
\text { dag }\end{array}$ & $\begin{array}{l}\text { Schoolmelk-dag } \\
\text { (=SMD) }\end{array}$ & $\begin{array}{l}\text { Frequentie totaal } \\
\begin{array}{c}N(\%) \\
N=113\end{array}\end{array}$ \\
\hline Suikerhoudend & Suikerhoudend & $16(14 \%)$ \\
\hline Zonder suiker & Suikerhoudend & $5(4 \%)$ \\
\hline Suikerhoudend & Zonder suiker & $17(15 \%)$ \\
\hline Zonder suiker & Zonder suiker & $75(66 \%)$ \\
\hline & Veranderaars & Stabielen \\
\hline Zonder suiker SMD & $17(77 \%)$ & $75(82 \%)$ \\
\hline Met suiker SMD & $5(23 \%)$ & $16(18 \%)$ \\
\hline
\end{tabular}

$66 \%$ drinkt op beide dagen dranken zonder suiker en $14 \%$ drinkt suikerhoudende dranken op beide dagen, dus de meeste kinderen veranderen niet $(80 \%)$.

$17 \%$ van de kinderen gaat van suikerhoudend naar zonder suiker, $4 \%$ verschuift de andere kant op.

De Chi-kwadraat toets laat een significante relatie zien tussen soort drank en dag: het aantal kinderen dat zonder suiker gaat drinken $(\mathrm{N}=17)$ is hoger dan verwacht, de andersom bewegers $(\mathrm{N}=5)$ lager dan verwacht. 


\section{Inzoomen op veranderaars 'suiker $\rightarrow$ zonder suiker'}

\section{Niet-schoolmelk-dag}

Schoolmelk-dag

N

Limonade, ranja, siroop, diksap

Water

1

Vruchtensap

Water

1

Limonade, ranja, siroop, diksap

Schoolmelk

5

Vruchtensap

Schoolmelk

1

Vruchtendrank

Schoolmelk

2

Gezoete melkdranken

Schoolmelk

Schoolmelk-karnemelk

Light-frisdranken

Light-frisdranken

Leeg
Limonade, ranja, siroop, diksap

Vruchtensap

Limonade, ranja, siroop, diksap

Vruchtendrank

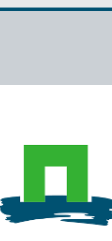

De dranken zonder suiker zijn op een schoolmelk-dag water (2x), school-(karne)- melk (10x) of light- frisdrank (2x).

10 van de 17 gaan van suikerhoudende dranken naar ongezoete zuivel, waarvan 1 kind van gezoete zuivel naar ongezoete zuivel.

2 kinderen gaan van suikerhoudende drank naar water.

10 van deze 17 kinderen dronken op de schoolmelk-dag (karne)melk vanuit het Schoolmelkprogramma. 


\section{Inzoomen op stabiele zonder-suiker groep $(\mathrm{N}=75)$}

\begin{tabular}{llc}
\hline Niet-schoolmelk-dag & Schoolmelk-dag & $\mathrm{N}$ \\
\hline Water & Water & 45 \\
\hline Water & Schoolmelk & 13 \\
\hline Water & Karnemelk & 1 \\
\hline Schoolmelk & Schoolmelk & 4 \\
Melk of karnemelk & Schoolmelk & 5 \\
\hline Schoolmelk* & Water & 2 \\
\hline Melkdranken zoetstof & Melkdranken zoetstof & 1 \\
\hline Light-frisdranken & Water & 1 \\
\hline Light-frisdranken & Light-frisdranken & 1 \\
\hline Leeg & Water & 1 \\
\hline Leeg & Schoolmelk & 1 \\
\hline
\end{tabular}

De kinderen die op beide dagen geen suikerhoudende dranken drinken $(\mathrm{N}=75)$, drinken over het algemeen water, schoolmelk of karnemelk.

15 van de 75 kinderen verschuiven van niets of water naar schoolmelk of karnemelk.

2 van de 75 verschuiven van schoolmelk naar water.

25 van deze 75 kinderen dronken op de schoolmelkdag (karne)melk vanuit het Schoolmelk-programma. 


\section{Hoeveel drinken kinderen op school?}




\section{Gemiddelde consumptie in $\mathrm{ml}$ (SD) per drankcategorie}

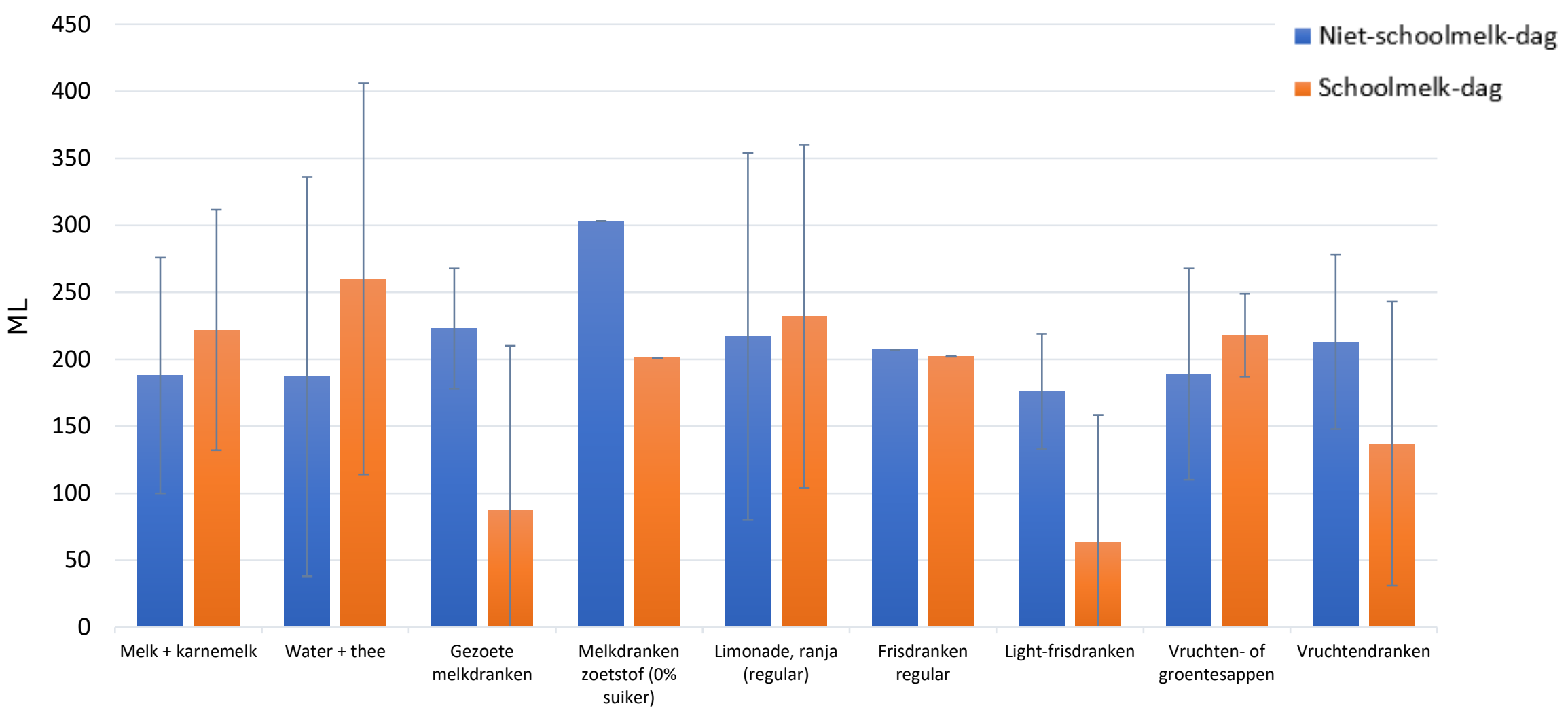




\section{Consumptie - over dranken heen}

\begin{tabular}{|c|c|c|c|}
\hline & $\begin{array}{l}\text { Niet-schoolmelk- } \\
\text { dag }\end{array}$ & Schoolmelk-dag & $\begin{array}{l}\text { Verschil- } \\
\text { score* }\end{array}$ \\
\hline \multicolumn{4}{|l|}{$N=113$} \\
\hline \multirow{2}{*}{$\begin{array}{l}\text { Totale consumptie in } \mathrm{ml} \\
\text { (SD) }\end{array}$} & $187(121)$ & $220(133)$ & $33(134)$ \\
\hline & \multicolumn{3}{|c|}{ Gepaarde t-toets: $p=0,011$} \\
\hline \multicolumn{4}{|c|}{ *Verschil-score = schoolmelk-dag - niet-schoolmelk-dag } \\
\hline & \multicolumn{3}{|c|}{$\begin{array}{l}\text { Op een schoolmelk-dag drinken de kinderen iets } \\
\text { meer ( } 33 \mathrm{ml} \text { ) dan op een niet-schoolmelk-dag } \\
\text { (over alle dranken heen) }\end{array}$} \\
\hline
\end{tabular}




\section{Verandering in hoeveelheid drinken tussen zuivel-groepen}

\begin{tabular}{llcc} 
Niet-schoolmelk-dag & \multicolumn{1}{l}{ Schoolmelk-dag } & N & Verandering in ml (SD)* \\
\hline Zuivel & Zuivel & 13 & $-18(102)$ \\
Geen zuivel & Zuivel & 24 & $43(134)$ \\
Zuivel & Geen zuivel & 5 & $-66(139)$ \\
Geen zuivel & Geen zuivel & 71 & $45(136)$
\end{tabular}

*Verandering in $\mathrm{ml}=$ schoolmelk-dag - niet-schoolmelk-dag 


\section{Verandering in hoeveelheid drinken tussen suiker-groepen}

\begin{tabular}{llcc}
\hline Niet-schoolmelk-dag & Schoolmelk-dag & N & Verandering in ml (SD)* \\
\hline Suikerhoudend & Suikerhoudend & 16 & $-10(98)$ \\
Zonder suiker & Suikerhoudend & 5 & $-70(81)$ \\
Suikerhoudend & Zonder suiker & 17 & $45(163)$ \\
Zonder suiker & Zonder suiker & 76 & $46(133)$
\end{tabular}

*Verandering in $\mathrm{ml}=$ schoolmelk-dag - niet-schoolmelk-dag

Sommige groepen lijken meer te gaan drinken, sommigen minder, maar de groepen verschillen niet significant van elkaar (SD toont grote spreiding tussen kinderen en dagen). 


\section{Samenvatting metingen op school}

- Water, (karne)melk en limonades zijn de meest gedronken dranken op school.

- De meeste kinderen drinken op beide dagen geen zuivel (63\%); $12 \%$ drinkt zuivel op beide dagen.

- De meeste kinderen drinken op beide dagen dranken zonder suiker $(67 \%) ; 14 \%$ drinkt suikerhoudende dranken op beide dagen.

- $21 \%$ verandert van geen zuivel (water of suikerhoudende dranken) naar (karne)melk op een schoolmelk-dag, terwijl $4 \%$ de andere kant op verschuift.

- $29 \%$ van de kinderen dronk op de schoolmelk-dag (karne)melk vanuit het Schoolmelkprogramma.

- Grote variatie tussen kinderen in hoeveel er gedronken wordt (60-300ml).

- Op een schoolmelk-dag wordt er iets meer gedronken $(33 \mathrm{ml})$, dit hangt niet samen met het drinkgedrag t.a.v. zuivel of suikerhoudende dranken. 


\section{Resultaten oudervragenlijst}

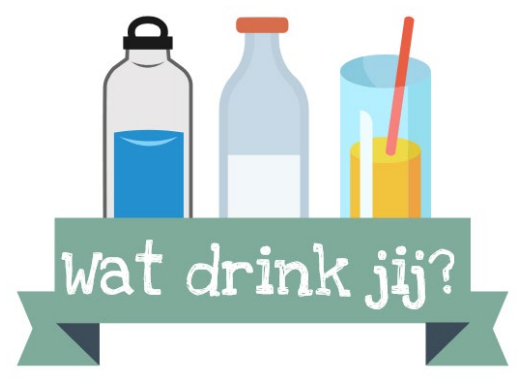




\section{Deelnemers oudervragenlijst}

\begin{tabular}{|lc|}
\hline & $\begin{array}{c}\text { Toestemming } \\
\text { ouders deelname N }\end{array}$ \\
\hline School 1 & 95 \\
\hline School 2 & 14 \\
\hline School 3 & 29 \\
\hline School 4 & 7 \\
\hline School 5 & 22 \\
\hline School 6 & 20 \\
\hline School 7 & 1 \\
\hline School 8 & 20 \\
\hline School 9 & 34 \\
\hline Totaal & 242 \\
\hline
\end{tabular}

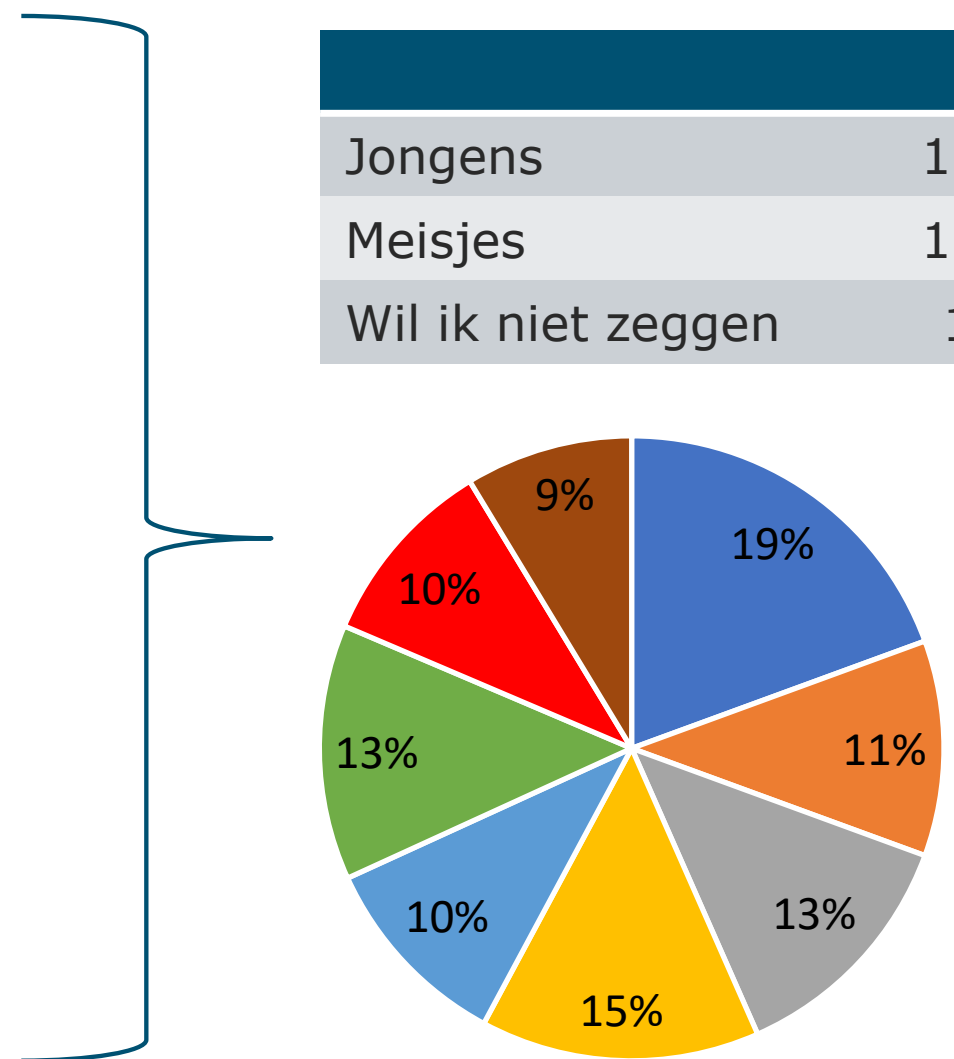

N $(\%)$

$133(55 \%)$

$108(45 \%)$

$1(0,4 \%)$ 


\section{Wat drinken kinderen bij verschillende eetmomenten?}

Leeswijzer: De volgende slides laten overzichten zien per eetmoment voor een schoolmelk-dag, een niet-schoolmelk-dag en een weekenddag.

Ouders kruisten aan welke dranken hun kind drinkt per eetmoment; zij konden meerdere opties aankruisen.

De frequenties zijn gesorteerd van hoog naar laag op basis van nietschoolmelkdag.

Vet gemarkeerde getallen geven aan dat dit percentage groter of kleiner lijkt t.o.v. de andere dagen (beschrijvend want exacte toetsing niet mogelijk). 


\section{Wat drinken kinderen bij het ontbijt: N (\%)?}

\begin{tabular}{|c|c|c|c|}
\hline$N=242$ & Niet-schoolmelk-dag* & Schoolmelk-dag* & Weekenddag* \\
\hline Melk + karnemelk & $127(52 \%)$ & $123(51 \%)$ & $123(51 \%)$ \\
\hline Water + thee zonder suiker & $109(45 \%)$ & $118(49 \%)$ & $114(47 \%)$ \\
\hline Limonade, ranja (regular) & $32(13 \%)$ & $26(11 \%)$ & $42(17 \%)$ \\
\hline Melkdranken zoetstof ( $0 \%$ suiker) & $23(10 \%)$ & $18(7 \%)$ & $25(10 \%)$ \\
\hline Gezoete melkdranken & $16(7 \%)$ & $14(6 \%)$ & $27(11 \%)$ \\
\hline Vruchten- of groentesappen (V\&G) & $14(6 \%)$ & $13(5 \%)$ & $33(14 \%)$ \\
\hline Plantaardige dranken & $10(4 \%)$ & $7(3 \%)$ & $8(3 \%)$ \\
\hline Vruchtendranken & $9(4 \%)$ & $5(2 \%)$ & $9(4 \%)$ \\
\hline Niets & $6(2 \%)$ & $2(1 \%)$ & $1(0.4 \%)$ \\
\hline Thee met suiker & $5(2 \%)$ & $6(2 \%)$ & $10(4 \%)$ \\
\hline Light-frisdranken & $2(1 \%)$ & $3(1 \%)$ & $2(1 \%)$ \\
\hline Frisdranken regular & $1(0.4 \%)$ & - & $1(0.4 \%)$ \\
\hline
\end{tabular}

* Ouder kon meerdere antwoordopties geven

Weinig verschil tussen schoolmelk en niet-schoolmelk-dag; Weekend iets vaker gezoete dranken en V\&G sappen 


\section{Wat drinken kinderen 's ochtends tussendoor: $\mathrm{N}(\%)$ ?}

\begin{tabular}{|c|c|c|c|c|}
\hline \multicolumn{2}{|l|}{$N=242$} & Niet-schoolmelk-dag* & Schoolmelk-dag* & Weekenddag* \\
\hline \multicolumn{2}{|l|}{ Water + thee zonder suiker } & $145(60 \%)$ & $146(60 \%)$ & $147(61 \%)$ \\
\hline \multicolumn{2}{|l|}{ Limonade, ranja (regular) } & $86(36 \%)$ & $85(35 \%)$ & $125(52 \%)$ \\
\hline \multicolumn{2}{|l|}{ Melk + karnemelk } & $26(11 \%)$ & $45(19 \%)$ & $31(13 \%)$ \\
\hline \multicolumn{2}{|c|}{ Vruchten- of groentesappen (V\&G) } & $17(7 \%)$ & $13(5 \%)$ & $23(10 \%)$ \\
\hline \multicolumn{2}{|l|}{ Vruchtendranken } & $11(5 \%)$ & $13(5 \%)$ & $19(8 \%)$ \\
\hline \multicolumn{2}{|c|}{ Melkdranken zoetstof (0\% suiker) } & $14(6 \%)$ & $12(5 \%)$ & $14(6 \%)$ \\
\hline \multicolumn{2}{|l|}{ Gezoete melkdranken } & $13(5 \%)$ & $10(4 \%)$ & $13(5 \%)$ \\
\hline \multicolumn{2}{|l|}{ Light-frisdranken } & $4(2 \%)$ & $5(2 \%)$ & $9(4 \%)$ \\
\hline \multicolumn{2}{|l|}{ Thee met suiker } & $2(1 \%)$ & $4(2 \%)$ & $7(3 \%)$ \\
\hline \multicolumn{2}{|l|}{ Plantaardige dranken } & $6(2 \%)$ & $5(2 \%)$ & $4(2 \%)$ \\
\hline \multicolumn{2}{|l|}{ Niets } & $1(0.4 \%)$ & $1(0.4 \%)$ & $3(1 \%)$ \\
\hline \multicolumn{2}{|l|}{ Frisdranken regular } & - & - & $1(0.4 \%)$ \\
\hline $\begin{array}{l}\text { * Ouder kon meerdere } \\
\text { antwoordopties geven }\end{array}$ & $\begin{array}{l}\text { Vake } \\
\text { Week }\end{array}$ & $\begin{array}{l}\text { arne)melk op schoo } \\
\text { d vaker limonades e }\end{array}$ & $\begin{array}{l}\text { lk-dag; } \\
\& G \text { sappen }\end{array}$ & \\
\hline
\end{tabular}




\section{Wat drinken kinderen bij de lunch: N (\%)?}

\begin{tabular}{|c|c|c|c|c|}
\hline \multicolumn{2}{|l|}{$N=242$} & Niet-schoolmelk-dag* & Schoolmelk-dag* & Weekenddag* \\
\hline \multicolumn{2}{|c|}{ Water + thee zonder suiker } & $124(51 \%)$ & $114(47 \%)$ & $116(48 \%)$ \\
\hline \multicolumn{2}{|l|}{ Melk + karnemelk } & $67(28 \%)$ & $106(44 \%)$ & $116(48 \%)$ \\
\hline \multicolumn{2}{|c|}{ Limonade, ranja (regular) } & $65(27 \%)$ & $45(19 \%)$ & $55(23 \%)$ \\
\hline \multicolumn{2}{|c|}{ Gezoete melkdranken } & $17(7 \%)$ & $12(5 \%)$ & $34(14 \%)$ \\
\hline \multicolumn{2}{|c|}{ Melkdranken zoetstof ( $0 \%$ suiker) } & $16(7 \%)$ & $16(7 \%)$ & $33(14 \%)$ \\
\hline \multicolumn{2}{|c|}{ Vruchten- of groentesappen } & $17(7 \%)$ & $16(7 \%)$ & $25(10 \%)$ \\
\hline \multicolumn{2}{|l|}{ Vruchtendranken } & $23(10 \%)$ & $17(7 \%)$ & $17(7 \%)$ \\
\hline \multicolumn{2}{|l|}{ Thee met suiker } & $1(0.4 \%)$ & $3(1 \%)$ & $9(4 \%)$ \\
\hline \multicolumn{2}{|l|}{ Plantaardige dranken } & $6(2 \%)$ & $7(3 \%)$ & $8(3 \%)$ \\
\hline \multicolumn{2}{|l|}{ Light-frisdranken } & $5(2 \%)$ & $4(2 \%)$ & $6(2 \%)$ \\
\hline \multicolumn{2}{|l|}{ Frisdranken regular } & $1(0.4 \%)$ & - & $2(1 \%)$ \\
\hline \multicolumn{2}{|l|}{ Niets } & - & $1(0.4 \%)$ & $1(0.4 \%)$ \\
\hline $\begin{array}{l}\text { * Ouder kon meerdere } \\
\text { antwoordopties geven }\end{array}$ & $\begin{array}{l}\text { Vaker (kar } \\
\text { Weekend }\end{array}$ & $\begin{array}{l}\text { )melk op schoolme } \\
\text { vaker (karne)melk }\end{array}$ & $\begin{array}{l}\text { g, minder vaak } \\
\text { nelkdranken met }\end{array}$ & $\begin{array}{l}\text { Ionades; } \\
\text { pete smaak }\end{array}$ \\
\hline
\end{tabular}




\section{Wat drinken kinderen bij 's middags tussendoor: $\mathrm{N}(\%)$ ?}

\begin{tabular}{|c|c|c|c|}
\hline$N=242$ & Niet-schoolmelk-dag* & Schoolmelk-dag* & Weekenddag* \\
\hline Limonade, ranja (regular) & $131(54 \%)$ & $126(52 \%)$ & $165(68 \%)$ \\
\hline Water + thee zonder suiker & $145(60 \%)$ & $149(62 \%)$ & $134(55 \%)$ \\
\hline Vruchten- of groentesappen (V\&G) & $22(9 \%)$ & $20(8 \%)$ & $33(14 \%)$ \\
\hline Vruchtendranken & $22(9 \%)$ & $21(9 \%)$ & $32(13 \%)$ \\
\hline Melk + karnemelk & $14(6 \%)$ & $30(12 \%)$ & $30(12 \%)$ \\
\hline Light-frisdranken & $8(3 \%)$ & $6(2 \%)$ & $16(7 \%)$ \\
\hline Frisdranken regular & $1(0.4 \%)$ & $2(1 \%)$ & $15(6 \%)$ \\
\hline Gezoete melkdranken & $9(4 \%)$ & $8(3 \%)$ & $13(5 \%)$ \\
\hline Melkdranken zoetstof ( $0 \%$ suiker) & $6(2 \%)$ & $6(2 \%)$ & $6(2 \%)$ \\
\hline Thee met suiker & $3(1 \%)$ & $5(2 \%)$ & $5(2 \%)$ \\
\hline Plantaardige dranken & $2(1 \%)$ & $2(1 \%)$ & $4(2 \%)$ \\
\hline Niets & $4(2 \%)$ & $4(2 \%)$ & $1(0.4 \%)$ \\
\hline
\end{tabular}

* Ouder kon meerdere Vaker (karne)melk op schoolmelk-dag; Weekend ook vaker (karne) antwoordopties geven melk, limonades en V\&G sappen, minder vaak water/ thee zonder suiker ${ }^{43}$ 


\section{Wat drinken kinderen bij het diner: N (\%)?}

\begin{tabular}{|c|c|c|c|c|}
\hline \multicolumn{2}{|l|}{$N=242$} & Niet-schoolmelk-dag* & Schoolmelk-dag* & Weekenddag* \\
\hline \multicolumn{2}{|l|}{ Water + thee zonder suiker } & $171(71 \%)$ & $170(70 \%)$ & $169(70 \%)$ \\
\hline \multicolumn{2}{|l|}{ Melk + karnemelk } & $45(19 \%)$ & $41(17 \%)$ & $63(26 \%)$ \\
\hline \multicolumn{2}{|l|}{ Limonade, ranja (regular) } & $46(19 \%)$ & $50(21 \%)$ & $49(20 \%)$ \\
\hline \multicolumn{2}{|l|}{ Niets } & $21(9 \%)$ & $24(10 \%)$ & $23(10 \%)$ \\
\hline \multicolumn{2}{|l|}{ Vruchtendranken } & $15(6 \%)$ & $18(7 \%)$ & $20(8 \%)$ \\
\hline \multicolumn{2}{|l|}{ Vruchten- of groentesappen } & $15(6 \%)$ & $17(7 \%)$ & $15(6 \%)$ \\
\hline \multicolumn{2}{|l|}{ Light-frisdranken } & $6(2 \%)$ & $7(3 \%)$ & $12(5 \%)$ \\
\hline \multicolumn{2}{|l|}{ Frisdranken regular } & $2(1 \%)$ & $4(2 \%)$ & $10(4 \%)$ \\
\hline \multicolumn{2}{|c|}{ Melkdranken zoetstof ( $0 \%$ suiker) } & $9(4 \%)$ & $7(3 \%)$ & $9(4 \%)$ \\
\hline \multicolumn{2}{|l|}{ Gezoete melkdranken } & $3(1 \%)$ & $4(2 \%)$ & $7(3 \%)$ \\
\hline \multicolumn{2}{|l|}{ Plantaardige dranken } & $7(3 \%)$ & $4(2 \%)$ & $3(1 \%)$ \\
\hline \multicolumn{2}{|l|}{ Thee met suiker } & $1(0.4 \%)$ & - & $2(1 \%)$ \\
\hline $\begin{array}{l}\text { * Ouder kon meerdere } \\
\text { antwoordopties geven }\end{array}$ & \multicolumn{4}{|c|}{$\begin{array}{l}\text { Weinig verschil tussen schoolmelk en niet-schoolmelk-dag; } \\
\text { Weekend meer kinderen die (karne)melk drinken }\end{array}$} \\
\hline
\end{tabular}




\section{Wat drinken kinderen 's avonds tussendoor: $\mathrm{N}(\%)$ ?}

\begin{tabular}{|c|c|c|c|}
\hline$N=242$ & Niet-schoolmelk-dag* & Schoolmelk-dag* & Weekenddag* \\
\hline Water + thee zonder suiker & $159(66 \%)$ & $159(66 \%)$ & $142(59 \%)$ \\
\hline Limonade, ranja (regular) & $64(26 \%)$ & $67(28 \%)$ & $82(34 \%)$ \\
\hline Niets & $42(17 \%)$ & $43(18 \%)$ & $39(16 \%)$ \\
\hline Vruchtendranken & $10(4 \%)$ & $15(6 \%)$ & $25(10 \%)$ \\
\hline Melk + karnemelk & $27(11 \%)$ & $26(11 \%)$ & $23(10 \%)$ \\
\hline Frisdranken regular & $8(3 \%)$ & $5(2 \%)$ & $23(10 \%)$ \\
\hline Light-frisdranken & $4(2 \%)$ & $4(2 \%)$ & $20(8 \%)$ \\
\hline Vruchten- of groentesappen & $10(4 \%)$ & $14(6 \%)$ & $15(6 \%)$ \\
\hline Gezoete melkdranken & $5(2 \%)$ & $4(2 \%)$ & $8(3 \%)$ \\
\hline Melkdranken zoetstof ( $0 \%$ suiker) & $5(2 \%)$ & $7(3 \%)$ & $5(2 \%)$ \\
\hline Thee met suiker & $4(2 \%)$ & $3(1 \%)$ & $4(2 \%)$ \\
\hline Plantaardige dranken & $2(1 \%)$ & $2(1 \%)$ & $2(1 \%)$ \\
\hline
\end{tabular}

* Ouder kon meerdere antwoordopties geven
Weinig verschil tussen schoolmelk en niet-schoolmelk-dag; Weekend minder vaak water, vaker limonadedranken \& frisdrank 


\section{Samenvatting oudervragenlijst: soort dranken}

- Bij het ontbijt, avondeten en na het avondeten lijkt er weinig invloed te zijn van het Schoolmelk-programma.

- Op een schoolmelk-dag lijken meer kinderen (karne)melk te drinken bij de eetmomenten 's ochtends tussendoor, bij de lunch en 's middags tussendoor.

- In het weekend lijkt er een tendens te zijn dat meer kinderen suikerhoudende dranken drinken, maar ook meer kinderen die zuiveldranken drinken (lunch, 's middags tussendoor en avondeten). 


\section{Verschillen tussen onder- en bovenbouw}

Leeswijzer: De volgende slides laten vergelijkbare overzichten zien voor een schoolmelk-dag en een niet-schoolmelk-dag opgesplitst voor onderbouw (gr 1 $\mathrm{t} / \mathrm{m} \mathrm{4}$ ) en bovenbouw ( $\mathrm{gr} 5 \mathrm{t} / \mathrm{m} 8$ ).

De frequenties zijn gesorteerd van hoog naar laag op basis van de onderbouw. 


\section{Wat drinkt onder- vs bovenbouw bij ontbijt: N (\%)}

\begin{tabular}{|c|c|c|c|c|}
\hline & $\begin{array}{c}\text { ONDERBOUW } \\
\text { Niet-schoolmelk-D* } \\
\mathrm{N}=140\end{array}$ & $\begin{array}{c}\text { ONDERBOUW } \\
\text { Schoolmelk-D* } \\
\quad \mathrm{N}=140\end{array}$ & $\begin{array}{l}\text { BOVENBOUW Niet- } \\
\text { schoolmelk-D* } \\
\mathrm{N}=102\end{array}$ & $\begin{array}{c}\text { BOVENBOUW } \\
\text { Schoolmelk-D* } \\
\mathrm{N}=102\end{array}$ \\
\hline Melk + karnemelk & $71(51 \%)$ & $72(51 \%)$ & $56(55 \%)$ & $51(50 \%)$ \\
\hline Water + thee zonder suiker & $62(44 \%)$ & $67(48 \%)$ & $47(46 \%)$ & $51(50 \%)$ \\
\hline Melkdranken zoetstof ( $0 \%$ suiker) & $16(11 \%)$ & $14(10 \%)$ & $7(7 \%)$ & $4(4 \%)$ \\
\hline Limonade, ranja (regular) & $18(13 \%)$ & $11(8 \%)$ & $14(14 \%)$ & $15(15 \%)$ \\
\hline Vruchten- of groentesappen & $13(9 \%)$ & $16(11 \%)$ & $4(4 \%)$ & $2(2 \%)$ \\
\hline Plantaardige dranken & $11(8 \%)$ & $8(6 \%)$ & $1(1 \%)$ & $1(1 \%)$ \\
\hline Gezoete melkdranken & $10(7 \%)$ & $6(4 \%)$ & $6(6 \%)$ & $8(8 \%)$ \\
\hline Vruchtendranken & $5(4 \%)$ & $4(3 \%)$ & $4(4 \%)$ & $1(1 \%)$ \\
\hline Niets & $4(3 \%)$ & $1(1 \%)$ & $2(2 \%)$ & $1(1 \%)$ \\
\hline Thee met suiker & $3(2 \%)$ & $3(2 \%)$ & $2(2 \%)$ & $3(3 \%)$ \\
\hline Light-frisdranken & $2(1 \%)$ & $2(1 \%)$ & - & $1(1 \%)$ \\
\hline Frisdranken regular & - & - & $1(1 \%)$ & - \\
\hline
\end{tabular}

* Ouder kon meerdere antwoordopties geven 


\section{Wat drinkt onder- vs bovenbouw 's ochtends tussendoor: N (\%)}

\begin{tabular}{|c|c|c|c|c|}
\hline & $\begin{array}{c}\text { ONDERBOUW } \\
\text { Niet-schoolmelk-D* } \\
\mathrm{N}=140\end{array}$ & $\begin{array}{c}\text { ONDERBOUW } \\
\text { Schoolmelk-D* } \\
\mathrm{N}=140\end{array}$ & $\begin{array}{c}\text { BOVENBOUW Niet- } \\
\text { schoolmelk-D* } \\
\mathrm{N}=102\end{array}$ & $\begin{array}{c}\text { BOVENBOUW } \\
\text { Schoolmelk-D* } \\
\mathrm{N}=102\end{array}$ \\
\hline Water + thee zonder suiker & $81(58 \%)$ & $83(59 \%)$ & $64(63 \%)$ & $63(62 \%)$ \\
\hline Limonade, ranja (regular) & $44(31 \%)$ & $46(33 \%)$ & $42(41 \%)$ & $39(38 \%)$ \\
\hline Melk + karnemelk & $17(12 \%)$ & $24(17 \%)$ & $9(9 \%)$ & $21(21 \%)$ \\
\hline Melkdranken zoetstof ( $0 \%$ suiker) & $11(8 \%)$ & $8(6 \%)$ & $3(3 \%)$ & $4(4 \%)$ \\
\hline Vruchten- of groentesappen & $10(7 \%)$ & $9(6 \%)$ & $7(7 \%)$ & $4(4 \%)$ \\
\hline Vruchtendranken & $5(4 \%)$ & $7(5 \%)$ & $11(11 \%)$ & $6(6 \%)$ \\
\hline Plantaardige dranken & $6(4 \%)$ & $4(3 \%)$ & - & $1(1 \%)$ \\
\hline Gezoete melkdranken & $2(1 \%)$ & $3(2 \%)$ & $11(11 \%)$ & $7(7 \%)$ \\
\hline Light-frisdranken & $2(1 \%)$ & $3(2 \%)$ & $2(2 \%)$ & $2(2 \%)$ \\
\hline Thee met suiker & $2(1 \%)$ & $2(1 \%)$ & - & $2(2 \%)$ \\
\hline Niets & $1(1 \%)$ & $1(1 \%)$ & - & - \\
\hline Frisdranken regular & - & - & - & - \\
\hline
\end{tabular}

* Ouder kon meerdere

Switch naar (karne)melk lijkt groter in bovenbouw; antwoordopties geven verder vergelijkbaar patroon 


\section{Wat drinkt onder- vs bovenbouw bij de lunch: N (\%)}

\begin{tabular}{|c|c|c|c|c|}
\hline & $\begin{array}{c}\text { ONDERBOUW } \\
\text { Niet-schoolmelk-D* } \\
\mathrm{N}=140\end{array}$ & $\begin{array}{c}\text { ONDERBOUW } \\
\text { Schoolmelk-D* } \\
\quad N=140\end{array}$ & $\begin{array}{c}\text { BOVENBOUW Niet- } \\
\text { schoolmelk-D* } \\
\mathrm{N}=102\end{array}$ & $\begin{array}{c}\text { BOVENBOUW } \\
\text { Schoolmelk-D* } \\
\quad N=102\end{array}$ \\
\hline Water + thee zonder suiker & $69(49 \%)$ & $67(48 \%)$ & $55(54 \%)$ & $47(46 \%)$ \\
\hline Melk + karnemelk & $33(24 \%)$ & $53(38 \%)$ & $34(33 \%)$ & $53(52 \%)$ \\
\hline Limonade, ranja (regular) & $37(26 \%)$ & $29(21 \%)$ & $28(27 \%)$ & $16(16 \%)$ \\
\hline Vruchtendranken & $15(11 \%)$ & $10(7 \%)$ & $8(8 \%)$ & $7(7 \%)$ \\
\hline Vruchten- of groentesappen & $12(9 \%)$ & $12(9 \%)$ & $5(5 \%)$ & $4(4 \%)$ \\
\hline Melkdranken zoetstof ( $0 \%$ suiker) & $8(6 \%)$ & $10(7 \%)$ & $8(8 \%)$ & $6(6 \%)$ \\
\hline Gezoete melkdranken & $7(5 \%)$ & $6(4 \%)$ & $10(10 \%)$ & $6(6 \%)$ \\
\hline Plantaardige dranken & $6(4 \%)$ & $7(5 \%)$ & - & - \\
\hline Light-frisdranken & $4(3 \%)$ & $3(2 \%)$ & $1(1 \%)$ & $1(1 \%)$ \\
\hline Thee met suiker & $1(1 \%)$ & $1(1 \%)$ & - & $2(2 \%)$ \\
\hline Frisdranken regular & $1(1 \%)$ & - & - & - \\
\hline Niets & - & $1(1 \%)$ & - & - \\
\hline
\end{tabular}

* Ouder kon meerdere antwoordopties geven

Switch naar (karne)melk lijkt groter in bovenbouw; verder vergelijkbaar patroon 


\section{Wat drinkt onder- vs bovenbouw 's middags tussendoor: N (\%)}

\begin{tabular}{|c|c|c|c|c|}
\hline & $\begin{array}{c}\text { ONDERBOUW } \\
\text { Niet-schoolmelk-D* } \\
\qquad=140\end{array}$ & $\begin{array}{c}\text { ONDERBOUW } \\
\text { Schoolmelk-D* } \\
\qquad N=140\end{array}$ & $\begin{array}{l}\text { BOVENBOUW Niet- } \\
\text { schoolmelk-D* } \\
\qquad N=102\end{array}$ & $\begin{array}{c}\text { BOVENBOUW } \\
\text { Schoolmelk-D* } \\
\text { N=102 }\end{array}$ \\
\hline Water + thee zonder suiker & $80(57 \%)$ & $81(58 \%)$ & $65(64 \%)$ & $68(67 \%)$ \\
\hline Limonade, ranja (regular) & $71(51 \%)$ & $70(50 \%)$ & $60(59 \%)$ & $56(55 \%)$ \\
\hline Vruchten- of groentesappen & $17(12 \%)$ & $15(11 \%)$ & $5(5 \%)$ & $5(5 \%)$ \\
\hline Vruchtendranken & $15(11 \%)$ & $13(9 \%)$ & $7(7 \%)$ & $8(8 \%)$ \\
\hline Melk + karnemelk & $8(6 \%)$ & $16(11 \%)$ & $6(6 \%)$ & $14(14 \%)$ \\
\hline Light-frisdranken & $7(5 \%)$ & $4(3 \%)$ & $1(1 \%)$ & $2(2 \%)$ \\
\hline Melkdranken zoetstof ( $0 \%$ suiker) & $3(2 \%)$ & $4(3 \%)$ & $3(3 \%)$ & $2(2 \%)$ \\
\hline Thee met suiker & $2(1 \%)$ & $4(3 \%)$ & $1(1 \%)$ & $1(1 \%)$ \\
\hline Niets & $2(1 \%)$ & $4(3 \%)$ & $2(2 \%)$ & - \\
\hline Gezoete melkdranken & $2(1 \%)$ & $3(2 \%)$ & $7(7 \%)$ & $5(5 \%)$ \\
\hline Plantaardige dranken & $2(1 \%)$ & $2(1 \%)$ & - & - \\
\hline Frisdranken regular & - & $2(1 \%)$ & $1(1 \%)$ & - \\
\hline
\end{tabular}

* Ouder kon meerdere antwoordopties geven 


\section{Wat drinkt onder- vs bovenbouw bij het diner: $\mathrm{N}(\%)$}

\begin{tabular}{|c|c|c|c|c|}
\hline & $\begin{array}{c}\text { ONDERBOUW } \\
\text { Niet-schoolmelk-D* } \\
\mathrm{N}=140\end{array}$ & $\begin{array}{c}\text { ONDERBOUW } \\
\text { Schoolmelk-D* } \\
\quad N=140\end{array}$ & $\begin{array}{c}\text { BOVENBOUW Niet- } \\
\text { schoolmelk-D* } \\
\mathrm{N}=102\end{array}$ & $\begin{array}{c}\text { BOVENBOUW } \\
\text { Schoolmelk-D* } \\
\quad \mathrm{N}=102\end{array}$ \\
\hline Water + thee zonder suiker & $103(74 \%)$ & $101(72 \%)$ & $68(67 \%)$ & $69(68 \%)$ \\
\hline Limonade, ranja (regular) & $25(18 \%)$ & $30(21 \%)$ & $21(21 \%)$ & $20(20 \%)$ \\
\hline Melk + karnemelk & $25(18 \%)$ & $21(15 \%)$ & $20(20 \%)$ & $20(20 \%)$ \\
\hline Niets & $9(6 \%)$ & $12(9 \%)$ & $12(12 \%)$ & $12(12 \%)$ \\
\hline Vruchten- of groentesappen & $9(6 \%)$ & $12(9 \%)$ & $6(6 \%)$ & $5(5 \%)$ \\
\hline Vruchtendranken & $8(6 \%)$ & $12(9 \%)$ & $7(7 \%)$ & $6(6 \%)$ \\
\hline Melkdranken zoetstof ( $0 \%$ suiker) & $6(4 \%)$ & $4(3 \%)$ & $3(3 \%)$ & $3(3 \%)$ \\
\hline Light-frisdranken & $4(3 \%)$ & $5(4 \%)$ & $2(2 \%)$ & $2(2 \%)$ \\
\hline Plantaardige dranken & $2(1 \%)$ & $3(2 \%)$ & $5(5 \%)$ & $1(1 \%)$ \\
\hline Gezoete melkdranken & $1(1 \%)$ & $1(1 \%)$ & $2(2 \%)$ & $3(3 \%)$ \\
\hline Frisdranken regular & $1(1 \%)$ & $1(1 \%)$ & $1(1 \%)$ & $3(3 \%)$ \\
\hline Thee met suiker & $1(1 \%)$ & - & - & - \\
\hline
\end{tabular}

* Ouder kon meerdere antwoordopties geven 


\section{Wat drinkt onder- vs bovenbouw 's avonds tussendoor: N (\%)}

\begin{tabular}{|c|c|c|c|c|}
\hline & $\begin{array}{c}\text { ONDERBOUW } \\
\text { Niet-schoolmelk-D* } \\
\mathrm{N}=140\end{array}$ & $\begin{array}{c}\text { ONDERBOUW } \\
\text { Schoolmelk-D* } \\
\quad \mathrm{N}=140\end{array}$ & $\begin{array}{c}\text { BOVENBOUW Niet- } \\
\text { schoolmelk-D* } \\
\mathrm{N}=102\end{array}$ & $\begin{array}{c}\text { BOVENBOUW } \\
\text { Schoolmelk-D* } \\
\mathrm{N}=102\end{array}$ \\
\hline Water + thee zonder suiker & $94(67 \%)$ & $97(69 \%)$ & $65(64 \%)$ & $62(61 \%)$ \\
\hline Limonade, ranja (regular) & $32(23 \%)$ & $32(23 \%)$ & $32(31 \%)$ & $35(34 \%)$ \\
\hline Niets & $20(14 \%)$ & $21(15 \%)$ & $22(22 \%)$ & $22(22 \%)$ \\
\hline Melk + karnemelk & $16(11 \%)$ & $9(6 \%)$ & $11(11 \%)$ & $17(17 \%)$ \\
\hline Vruchten- of groentesappen & $6(4 \%)$ & $7(5 \%)$ & $4(4 \%)$ & $7(7 \%)$ \\
\hline Vruchtendranken & $4(3 \%)$ & $13(9 \%)$ & $6(6 \%)$ & $2(2 \%)$ \\
\hline Light-frisdranken & $3(2 \%)$ & $4(3 \%)$ & $1(1 \%)$ & - \\
\hline Melkdranken zoetstof ( $0 \%$ suiker) & $2(1 \%)$ & $3(2 \%)$ & $3(3 \%)$ & $4(4 \%)$ \\
\hline Frisdranken regular & $2(1 \%)$ & $1(1 \%)$ & $6(6 \%)$ & $4(4 \%)$ \\
\hline Plantaardige dranken & $1(1 \%)$ & $1(1 \%)$ & $1(1 \%)$ & $1(1 \%)$ \\
\hline Plantaardige dranken & $1(1 \%)$ & $1(1 \%)$ & $1(1 \%)$ & $1(1 \%)$ \\
\hline Gezoete melkdranken & $1(1 \%)$ & - & $4(4 \%)$ & $4(4 \%)$ \\
\hline Thee met suiker & - & - & $4(1 \%)$ & $3(3 \%)$ \\
\hline
\end{tabular}

* Ouder kon meerdere antwoordopties geven 


\section{Samenvatting exploratie onder- vs bovenbouw}

- Patronen qua soort drinken op niet-schoolmelk-dag versus schoolmelk-dag lijken grotendeels vergelijkbaar voor de onderbouw en bovenbouw.

- Voor een aantal eetmomenten lijkt de verschuiving naar (karne)melk op een schoolmelk-dag groter te zijn voor de bovenbouw vergeleken met de onderbouw: 's ochtends tussendoor, lunch \& 's avonds tussendoor. 


\section{Welke soort melk drinken de kinderen meestal $(\mathrm{N}=242)$ ?}

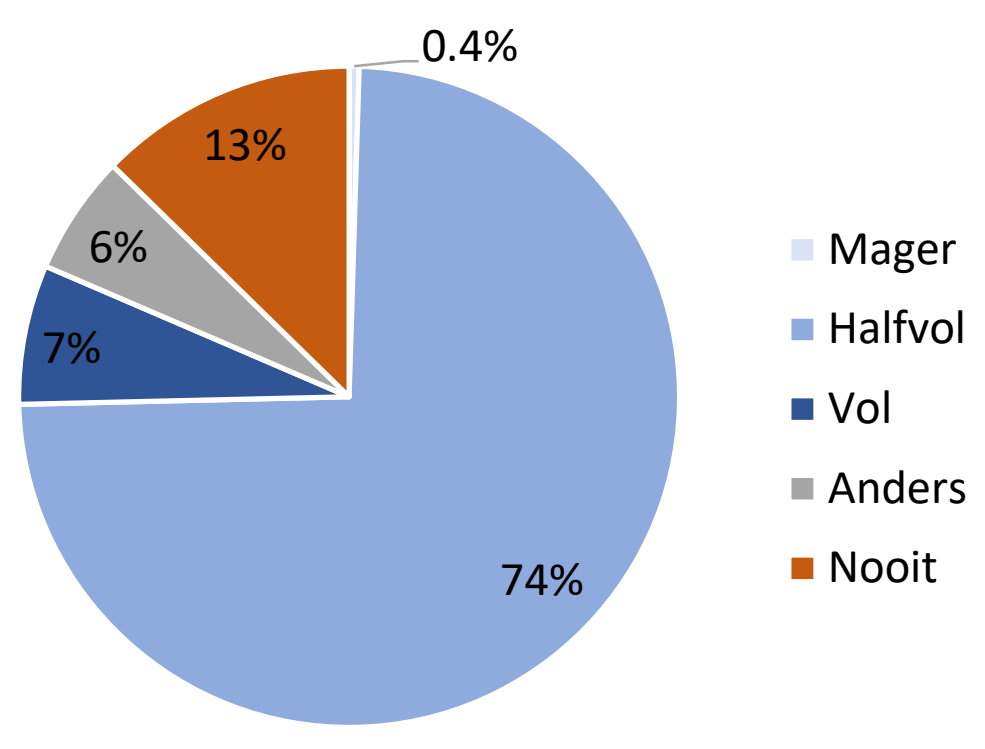

Als basisschoolkinderen melk drinken, dan is dit meestal halfvolle melk (74\%). $13 \%$ drinkt nooit melk. 


\section{Belang melk \& karnemelk}

\begin{tabular}{|c|c|c|c|c|c|}
\hline Stellingen $*$ & $\begin{array}{c}\text { Gem. } \pm \text { SD } \\
\text { Onderbouw } \\
(N=143)\end{array}$ & $\begin{array}{c}\text { Gem. } \pm \text { SD } \\
\text { Bovenbouw } \\
(N=98)\end{array}$ & $\begin{array}{c}\text { Gem. } \pm \text { SD } \\
\text { Totaal } \\
(\mathrm{N}=241)\end{array}$ & $\begin{array}{c}\% \text { Eens } \\
(\text { Score } 4+5)\end{array}$ & $\begin{array}{c}\% \text { Oneens } \\
(\text { Score } 1+2)\end{array}$ \\
\hline $\begin{array}{l}\text { Ik vind het belangrijk dat mijn kind elke } \\
\text { dag melk of karnemelk drinkt }\end{array}$ & $3,6 \pm 1,2^{a}$ & $3,3 \pm 1,3^{b}$ & $3,5 \pm 1,2$ & $60 \%$ & $21 \%$ \\
\hline $\begin{array}{l}\text { Mijn kind mag zelf kiezen welk drinken } \\
\text { hij/zij meeneemt naar school }\end{array}$ & $2,3 \pm 1,0$ & $2,2 \pm 1,0$ & $2,3 \pm 1,0$ & $15 \%$ & $70 \%$ \\
\hline $\begin{array}{l}\text { Ik vind het onhandig om melk of } \\
\text { karnemelk mee naar school te geven }\end{array}$ & $3,0 \pm 1,3$ & $3,0 \pm 1,4$ & $3,0 \pm 1,4$ & $44 \%$ & $40 \%$ \\
\hline $\begin{array}{l}\text { Ik vind melk en karnemelk gezond voor } \\
\text { kinderen }\end{array}$ & $3,9 \pm 0,9^{a}$ & $3,5 \pm 1,1^{b}$ & $3,7 \pm 1,0$ & $72 \%$ & $11 \%$ \\
\hline $\begin{array}{l}\text { Ik vind melk en karnemelk onnodig voor } \\
\text { kinderen }\end{array}$ & $1,8 \pm 0,9$ & $2,0 \pm 1,1$ & $1,8 \pm 0,9$ & $7 \%$ & $78 \%$ \\
\hline
\end{tabular}

- De meeste ouders ( $\geq 72 \%$ ) vinden (karne)melk gezond voor kinderen en niet onnodig.

- Een iets lager percentage (60\%) vindt het belangrijk dat hun kind elke dag (karne)melk drinkt.

- Onderbouw ouders scoren hoger op gezondheidsaspect + belang van elke dag (karne)melk $(p<0.05)$.

- De meeste kinderen (70\%) mogen niet zelf kiezen welke drank ze mee naar school willen.

- $44 \%$ van de ouders vindt (karne)melk mee nar school geven onhandig. 


\section{Voorkeuren melk \& karnemelk}

\begin{tabular}{|c|c|c|c|c|c|}
\hline Stellingen* & $\begin{array}{c}\text { Gem. } \pm \text { SD } \\
\text { Onderbouw } \\
(N=134)\end{array}$ & $\begin{array}{c}\text { Gem. } \pm \text { SD } \\
\text { Bovenbouw } \\
\quad(N=92)\end{array}$ & $\begin{array}{c}\text { Gem. } \pm \text { SD } \\
\text { Totaal } \\
(N=226)\end{array}$ & $\begin{array}{c}\% \text { Eens } \\
\text { (Score } 4+5)\end{array}$ & $\begin{array}{c}\% \text { Oneens } \\
(\text { Score } 1+2)\end{array}$ \\
\hline Mijn kind vindt melk lekker & $3,7 \pm 1,2$ & $3,5 \pm 1,3$ & $3,6 \pm 1,2$ & $68 \%$ & $20 \%$ \\
\hline $\begin{array}{l}\text { Mijn kind vindt karnemelk } \\
\text { lekker }\end{array}$ & $1,8 \pm 1,0$ & $2,0 \pm 1,0$ & $1,9 \pm 1,0$ & $12 \%$ & $82 \%$ \\
\hline & & & \multicolumn{3}{|c|}{ Paired t-test: $p=0,02$} \\
\hline Ik (ouder) vind melk lekker & $3,5 \pm 1,4$ & $3,5 \pm 1,3$ & $3,5 \pm 1,3$ & $62 \%$ & $23 \%$ \\
\hline $\begin{array}{l}\text { Ik (ouder) vind karnemelk } \\
\text { lekker }\end{array}$ & $2,4 \pm 1,5$ & $2,9 \pm 1,4$ & $2,6 \pm 1,5$ & $35 \%$ & $55 \%$ \\
\hline
\end{tabular}

Paired t-test: $p=0,57$

- Melk wordt lekkerder gevonden dan karnemelk: het verschil tussen melk en karnemelk is groter bij kinderen dan ouders.

- $\mathrm{Er}$ is een significant positieve correlatie tussen voorkeur ouder en kind voor zowel melk $(r=0,44$; $p=<0,001)$ als voor karnemelk $(r=0,44 ; p=<0,001)$.

- Geen verschil tussen onderbouw en bovenbouw. 


\section{Evaluatie Schoolmelk-programma}

\begin{tabular}{|c|c|c|c|c|c|}
\hline Stellingen* & $\begin{array}{c}\text { Gem. } \pm \text { SD } \\
\text { Onderbouw } \\
(N=139)\end{array}$ & $\begin{array}{c}\text { Gem. } \pm \text { SD } \\
\text { Bovenbouw } \\
\quad(N=98)\end{array}$ & $\begin{array}{c}\text { Gem. } \pm \text { SD } \\
\text { Totaal } \\
(\mathrm{N}=237)\end{array}$ & $\begin{array}{c}\% \text { Eens } \\
\text { (Score } \\
4+5)\end{array}$ & $\begin{array}{c}\% \text { Oneens } \\
\text { (Score } \\
1+2)\end{array}$ \\
\hline $\begin{array}{l}\text { Ik vind het fijn dat de school van mijn kind } \\
\text { deelneemt aan het Schoolmelk-programma }\end{array}$ & $3,9 \pm 1,2^{a}$ & $3,6 \pm 1,2^{b}$ & $3,0 \pm 1,2$ & $66 \%$ & $14 \%$ \\
\hline $\begin{array}{l}\text { Mijn kind vindt het Schoolmelk-programma } \\
\text { op school plezierig }\end{array}$ & $3,5 \pm 1,1^{a}$ & $3,2 \pm 1,2^{b}$ & $3,4 \pm 1,1$ & $49 \%$ & $19 \%$ \\
\hline $\begin{array}{l}\text { Door het Schoolmelk-programma is mijn } \\
\text { kind melk lekkerder gaan vinden }\end{array}$ & $2,4 \pm 1,1$ & $2,2 \pm 1,1$ & $2,3 \pm 1,0$ & $13 \%$ & $62 \%$ \\
\hline $\begin{array}{l}\text { Door het Schoolmelk-programma is mijn } \\
\text { kind karnemelk lekkerder gaan vinden }\end{array}$ & $1,9 \pm 0,9$ & $1,7 \pm 0,9$ & $1,8 \pm 0,9$ & $4 \%$ & $80 \%$ \\
\hline
\end{tabular}

- $66 \%$ van de ouders vindt het fijn dat school deelneemt aan het Schoolmelk-programma

- De helft van de kinderen vindt het Schoolmelk-programma plezierig (ouder-gerapporteerd)

- Voor beide stellingen scoren onderbouw-ouders hoger dan bovenbouw-ouders $(p<0.05)$

- Het Schoolmelk-programma leidt niet tot een hogere kind-voorkeur voor melk of karnemelk 


\section{Effecten Schoolmelk-programma (op kind)}

\begin{tabular}{|c|c|c|c|c|c|}
\hline Stellingen* & $\begin{array}{c}\text { Gem. } \pm \text { SD } \\
\text { Onderbouw } \\
(N=139)\end{array}$ & $\begin{array}{c}\text { Gem. } \pm \text { SD } \\
\text { Bovenbouw } \\
(N=98)\end{array}$ & $\begin{array}{c}\text { Gem. } \pm \text { SD } \\
\text { Totaal } \\
(\mathrm{N}=237)\end{array}$ & $\begin{array}{c}\% \text { Eens } \\
(\text { Score } 4+5)\end{array}$ & $\begin{array}{l}\% \text { Oneens } \\
\text { (Score } 1+2)\end{array}$ \\
\hline $\begin{array}{l}\text { Door het Schoolmelk-programma is mijn } \\
\text { kind meer melk/ karnemelk gaan drinken }\end{array}$ & $2,4 \pm 1,2$ & $2,1 \pm 1,3$ & $2,3 \pm 1,3$ & $19 \%$ & $65 \%$ \\
\hline $\begin{array}{l}\text { Door het Schoolmelk-programma is mijn } \\
\text { kind meer andere dranken gaan drinken }\end{array}$ & $1,9 \pm 0,9$ & $1,6 \pm 0,8$ & $1,8 \pm 0,9$ & $3 \%$ & $83 \%$ \\
\hline $\begin{array}{l}\text { Door het Schoolmelk-programma is mijn } \\
\text { kind minder andere dranken gaan drinken }\end{array}$ & $2,0 \pm 1,0$ & $1,8 \pm 0,8$ & $1,9 \pm 0,9$ & $5 \%$ & $80 \%$ \\
\hline
\end{tabular}

- Eén op de vijf ouders (19\%) geeft aan dat hun kind door het Schoolmelk-programma meer (karne)melk is gaan drinken; $65 \%$ geeft aan dat dit niet zo is.

- De meeste ouders ( $\geq 80 \%$ ) geven aan dat hun kind niet meer of minder van andere dranken is gaan drinken door het Schoolmelk-programma.

- Er zijn geen significante verschillen tussen onderbouw en bovenbouw. 


\section{Door het Schoolmelk-programma is mijn kind meer andere dranken gaan drinken: $\mathrm{N}=7(3 \%)$ eens}

Van welke soort drank is uw kind meer gaan drinken?
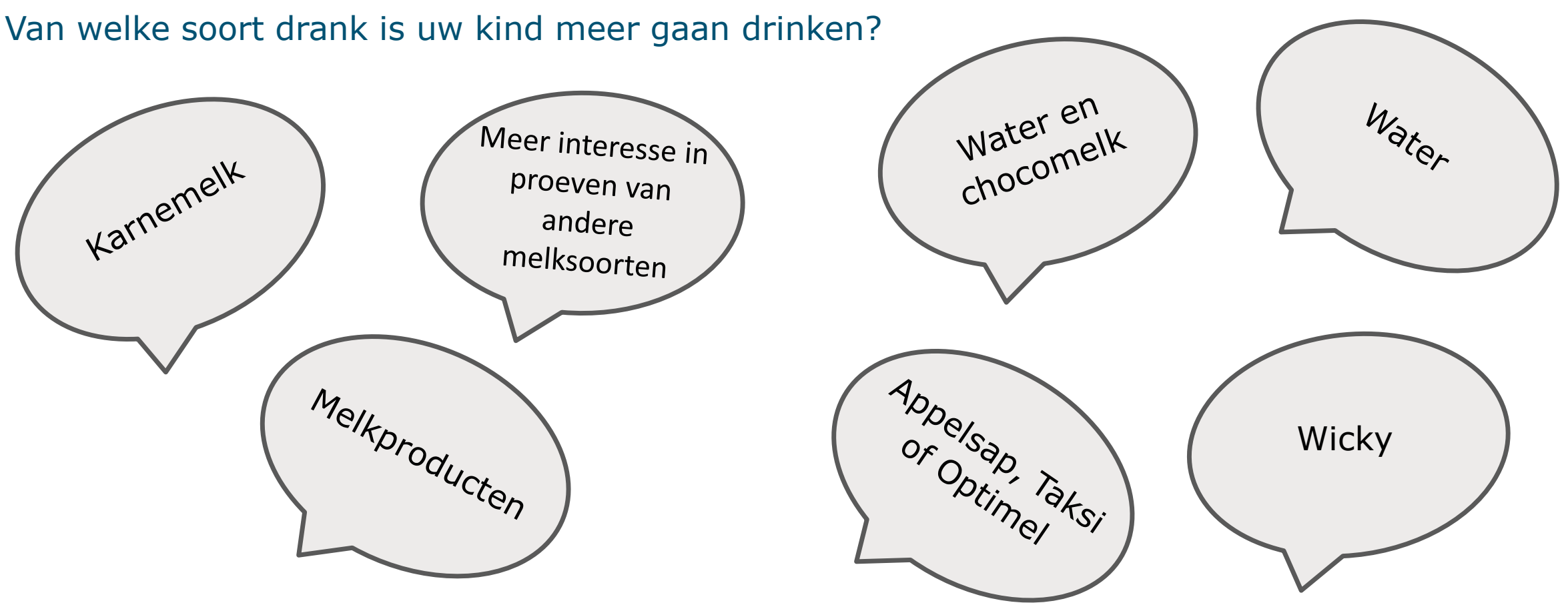


\section{Door het Schoolmelk-programma is mijn kind minder andere dranken gaan drinken: $\mathrm{N}=12(5 \%)$ eens}

Van welke soort drank is uw kind minder gaan drinken?

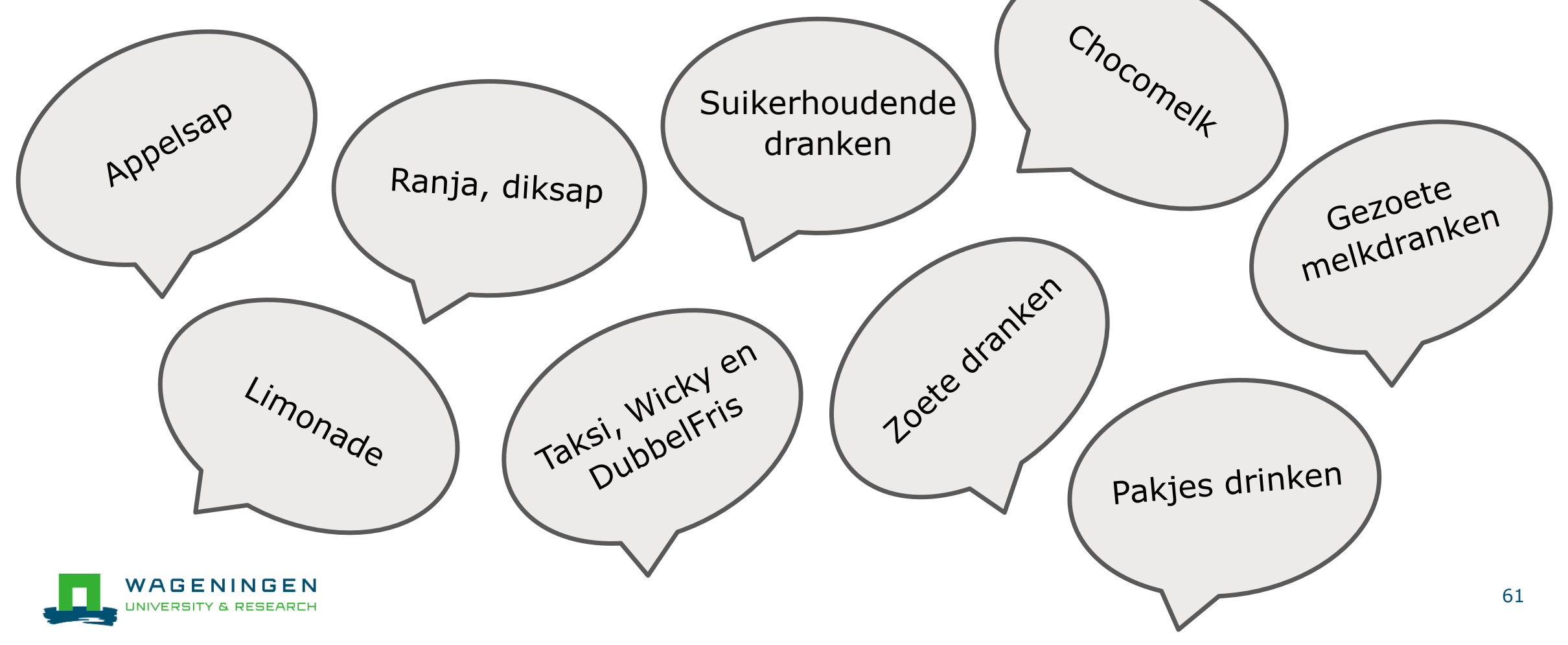




\section{Effecten Schoolmelk-programma (op gezin)}

\begin{tabular}{|c|c|c|c|c|c|}
\hline Stellingen* & $\begin{array}{l}\text { Gem. } \pm \text { SD } \\
\text { onderbouw } \\
(N=138)\end{array}$ & $\begin{array}{c}\text { Gem. } \pm \mathrm{SD} \\
\text { bovenbouw } \\
(\mathrm{N}=98)\end{array}$ & $\begin{array}{c}\text { Gem. } \pm \text { SD totaal } \\
\qquad(N=236)\end{array}$ & $\begin{array}{c}\% \text { Eens } \\
\text { (Score } \\
4+5)\end{array}$ & $\begin{array}{c}\% \text { Oneens } \\
(\text { Score } 1+2)\end{array}$ \\
\hline $\begin{array}{l}\text { Door het Schoolmelk-programma } \\
\text { heeft ons gezin ander drinken in } \\
\text { huis gehaald }\end{array}$ & $1,7 \pm 0,7$ & $1,7 \pm 0,8$ & $1,7 \pm 0,8$ & $2 \%$ & $87 \%$ \\
\hline $\begin{array}{l}\text { Door het Schoolmelk-programma } \\
\text { is ons gezin meer melk/karnemelk } \\
\text { gaan drinken }\end{array}$ & $1,9 \pm 0,9$ & $1,7 \pm 0,8$ & $1,8 \pm 0,8$ & $5 \%$ & $85 \%$ \\
\hline
\end{tabular}

- De meeste ouders ( $\geq 85 \%$ ) geven aan dat ze geen ander drinken in huis gehaald hebben door het Schoolmelk-programma; ook is het gezin niet meer (karne)melk gaan drinken.

- Geen verschil tussen onderbouw en bovenbouw. 


\section{Discussie}




\section{Hoofdbevindingen 1}

- $29 \%$ van de deelnemende kinderen dronk op de schoolmelk-dag (karne)melk vanuit het Schoolmelk-programma.

- Water, (karne)melk en limonades zijn de meest gedronken dranken op school.

- De meeste kinderen drinken op een niet-schoolmelk-dag en schoolmelk-dag vergelijkbare dranken: $63 \%$ drinkt op beide schooldagen geen zuivel, $66 \%$ drinkt op beide dagen dranken zonder suiker en 59\% drinkt precies dezelfde drank(categorie).

- Voor $21 \%$ van de kinderen lijkt schoolmelk op school tot een verschuiving te leiden richting ongezoete zuivel 'ten koste van' water ( 3 op de 5) en suikerhoudende dranken (2 op de 5); 4\% van de kinderen verschuift van zuivel naar niet zuivel. 


\section{Hoofdbevindingen 2}

- Er is veel variatie tussen kinderen in hoeveel zij drinken op school (60-300ml).

- Op een schoolmelk-dag wordt er iets meer $(33 \mathrm{ml})$ gedronken, dit hangt niet samen met het drinkgedrag t.a.v. zuivel of suikerhoudende dranken.

- $19 \%$ van de ouders gaf aan dat hun kind meer (karne)melk is gaan drinken door het Schoolmelk-programma - dit is vergelijkbaar met de verschuiving van $21 \%$ uit de metingen op school.

- De oudervragenlijst geeft aan dat deze verschuiving plaats lijkt te vinden tijdens de eetmomenten: 's ochtends tussendoor, bij de lunch en 's middags tussendoor. Bij de andere eetmomenten lijkt er geen invloed te zijn van het Schoolmelk-programma. 


\section{Hoofdbevindingen 3}

- De patronen op niet-schoolmelk-dag en schoolmelk-dag lijken grotendeels vergelijkbaar voor de onderbouw en bovenbouw, waarbij op een aantal eetmomenten de verschuiving naar (karne)melk op een schoolmelk-dag in de bovenbouw groter lijkt te zijn dan in de onderbouw.

- Ouders geven aan dat de meeste kinderen niet meer of minder andere dranken zijn gaan drinken door het Schoolmelk-programma.

- Voorkeur kind voor (karne)melk is niet gestegen door het Schoolmelk-programma.

- Geen veranderingen thuis t.a.v. drinkgedrag gezin door het Schoolmelk-programma.

- $66 \%$ van de ouders vindt deelname school aan Schoolmelk-programma fijn; $49 \%$ van de kinderen vindt deelname aan het programma plezierig (ouder-gerapporteerd); Onderbouw-ouders geven hier hogere scores dan bovenbouw-ouders. 


\section{Discussiepunten 1}

- Minder dan $1 / 3^{e}$ van de deelnemende kinderen maakt gebruik van schoolmelk

$\rightarrow$ Dit is een relatief kleine groep, dit beperkt mogelijk de effecten van het Schoolmelkprogramma.

- Op één school was er water-drink-beleid; daar waren meer kinderen die water dronken op school $\rightarrow$ Mogelijk leidt dit tot een plafondeffect voor schoolmelk.

- Deelname onderzoek (41\%) was lager dan verwacht door school (72\%). Het is mogelijk dat de deelnemende groep anders was dan de niet-deelnemers (bijv. kinderen met toestemming doen vaker mee aan het Schoolmelk-programma). 


\section{Discussiepunten 2}

- Soms was er schoolmelk over, zodat de school ook schoolmelk schonk op een nietschoolmelk-dag (bijv. Almere), dit kan enige invloed hebben gehad op de resultaten.

- Het is mogelijk dat kinderen door de onderzoekssituatie iets vaker hun beker leeg dronken. Echter de situatie was vergelijkbaar voor de niet-schoolmelk-dag en de schoolmelkdag. Daarnaast waren de onderzoekers niet aanwezig in de klas, dus we verwachten dat het effect hiervan verwaarloosbaar was.

- Het hangt af van het individuele eetpatroon van het kind welke verandering/ situatie t.a.v. drinken wenselijk is (bijv. de verandering van 'water naar zuivel' is positief vanuit zuiveloogpunt, maar mogelijk minder gunstig vanuit calorisch oogpunt). 


\section{Discussiepunten 3}

- Er zijn zowel objectieve metingen (op school) uitgevoerd alsook zelf-gerapporteerde ervaringen en veranderingen $\rightarrow$ dit geeft samen een goed beeld van de situatie.

- De metingen op school waren gericht op de bovenbouw, terwijl de oudervragenlijst gericht was op alle leeftijdsgroepen. Hierdoor was het mogelijk om naar een bredere leeftijdsgroep te kijken en leeftijdsverschillen te exploreren.

- Het feit dat ouders meerdere antwoordopties konden aankruisen bij wat hun kind meestal drinkt per eetmoment maakte de vragenlijst realistischer, maar tevens de interpretatie van de antwoorden complexer. 


\section{Aanbevelingen}

- Vervolgonderzoek is nodig om uitspraken te doen over het effect van het drinkmoment (ochtendpauze of lunch) op de acceptatie en deelname aan het Schoolmelk-programma.

- Verschillen tussen onderbouw en bovenbouw verder onderzoeken met objectieve metingen.

- Verder onderzoek naar het relatief lage gebruik van schoolmelk: welke factoren spelen hierbij een rol en heeft water-drink-beleid invloed hierop?

- Op een schoolmelk-dag dronken kinderen iets meer. Mogelijk leidt het Schoolmelkprogramma tot iets meer aandacht voor het drinkmoment of is de tijd om te drinken net wat langer. Interessant om dit mee te nemen in verder onderzoek.

- Verder onderzoek naar de invloed van deelname school aan Schoolmelk-programma op de keuze die ouders en kinderen maken voor soort drinken op school met herhaaldelijke metingen gedurende de looptijd van het programma en erna. 


\section{Conclusie}

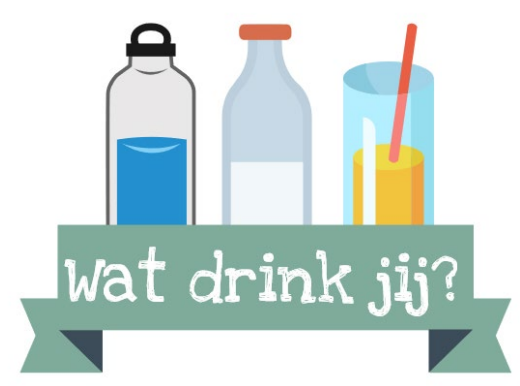




\section{Conclusies}

- Water, (karne)melk en limonades zijn de meest gedronken dranken op school.

- Van de deelnemende kinderen (groep 5 t/m 8) dronk $29 \%$ (karne)melk vanuit het Schoolmelk-programma.

- Voor de meeste kinderen heeft deelname van de school aan het Schoolmelk-programma geen invloed op wat ze drinken.

- Voor circa 20\% van de kinderen lijkt het Schoolmelk-programma hen te stimuleren om meer (karne)melk te drinken, in plaats van water of suikerhoudende dranken; terwijl 4\% de andere kant op verschuift (van zuivel naar geen zuivel). 


\section{Referenties}

- Rijksinstituut voor Volksgezondheid en Miliue (RIVM). Voedselconsumptiepeiling 20122016. Available from: https://www.wateetnederland.nl/

- Gezondheidsraad. Zuivel - Achtergronddocument bij Richtlijnen goede voeding 2015.

- Luger, M., et al. Sugar-Sweetened Beverages and Weight Gain in Children and Adults: A Systematic Review from 2013 to 2015 and a Comparison with Previous Studies. Obesity facts, 2017. 10(6): p. 674-693. 


\section{Met dank aan:}

- Marije Kea \& Odette Paling voor hun hulp bij de metingen op school

- De deelnemende scholen, kinderen en ouders

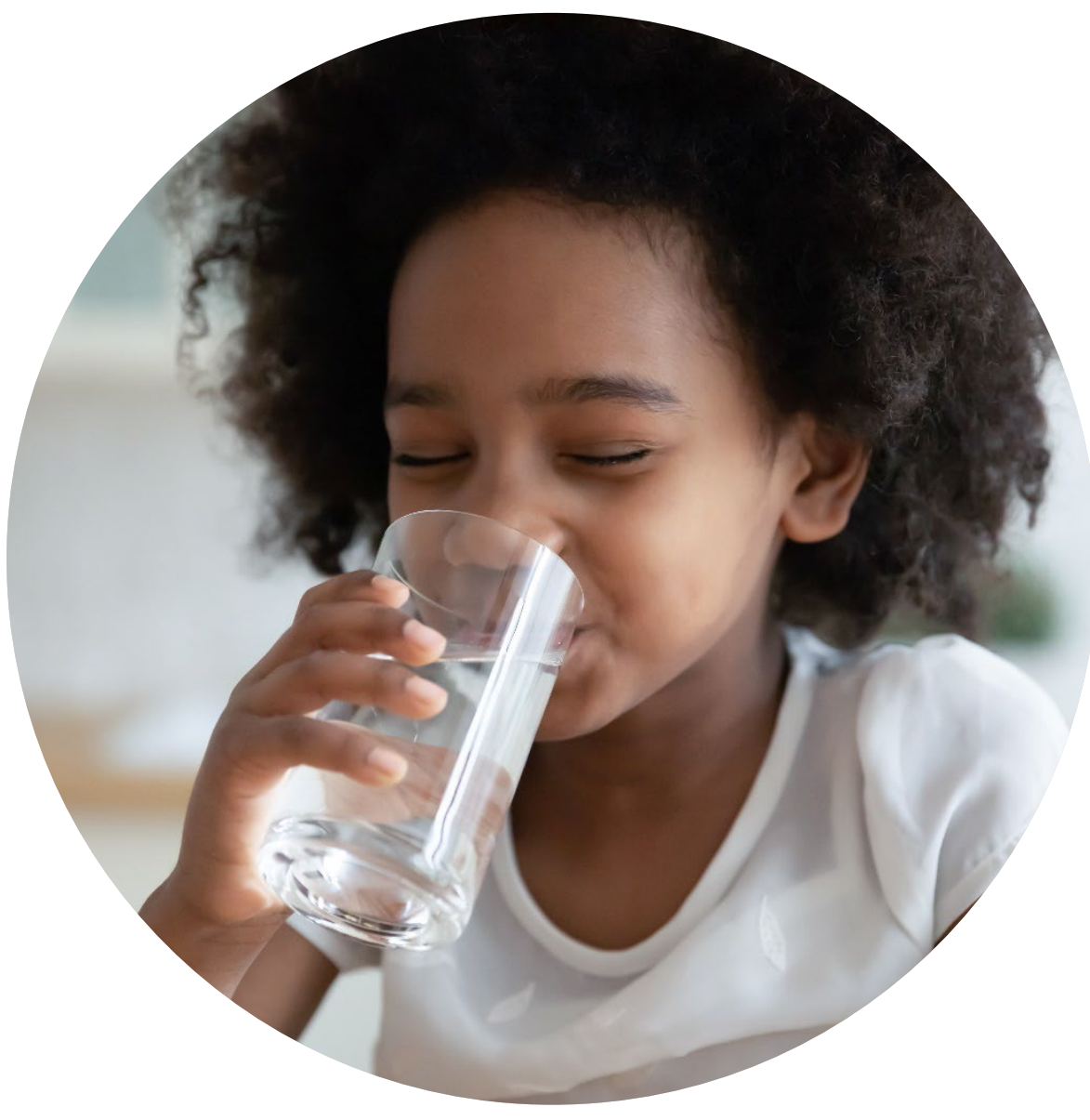




\section{Bijlage}




\section{Consumptie in $\mathrm{ml}$ (SD) bij kinderen die op beide dagen hetzelfde dronken $(\mathrm{N}=67 \rightarrow 59 \%$ van totaal)}

\begin{tabular}{|c|c|c|c|}
\hline & Niet-schoolmelk-dag & Schoolmelk-dag & P-verschil \\
\hline Water $(\mathrm{N}=45)$ & $196(153)$ & $260(155)$ & 0,005 \\
\hline Melk + karnemelk $(\mathrm{N}=9)$ & $207(42)$ & $218(99)$ & 0,69 \\
\hline Limonade, ranja $(\mathrm{N}=8)$ & $190(117)$ & $215(125)$ & 0,13 \\
\hline Gezoete melkdranken $(\mathrm{N}=2)$ & $223(45)$ & $87(123)$ & Kan niet $\mathrm{N}=2$ \\
\hline Melkdranken zoetstof $(\mathrm{N}=1)$ & 303 & 201 & - \\
\hline Light-frisdranken $(\mathrm{N}=1)$ & 126 & 171 & - \\
\hline Vruchtendranken $(\mathrm{N}=1)$ & 109 & 204 & - \\
\hline
\end{tabular}

